OPEN ACCESS

Edited by: Andrew Beharry, University of Toronto Mississauga,

Canada

Reviewed by:

José Carlos Menéndez, Complutense University of Madrid,

Spain

Edith Amuhaya,

United States International

University-Africa, Kenya

*Correspondence:

Gurcan Gunaydin gurcangunaydin@hacettepe.edu.tr

Seylan Ayan

seylan.ayan@bilkent.edu.tr

${ }^{\dagger}$ These authors have contributed equally to this work

Specialty section:

This article was submitted to Medicinal and Pharmaceutical Chemistry,

a section of the journal Frontiers in Chemistry

Received: 26 March 2021

Accepted: 19 July 2021

Published: 02 August 2021

Citation:

Gunaydin G, Gedik ME and Ayan S (2021) Photodynamic Therapy for the Treatment and Diagnosis of Cancer-A Review of the Current Clinical Status.

Front. Chem. 9:686303.

doi: $10.3389 /$ fchem.2021.686303

\section{Photodynamic Therapy for the Treatment and Diagnosis of Cancer-A Review of the Current Clinical Status}

\author{
Gurcan Gunaydin $^{1 * \dagger}$, M. Emre Gedik ${ }^{1 \dagger}$ and Seylan Ayan ${ }^{2 * \dagger}$ \\ ${ }^{1}$ Department of Basic Oncology, Hacettepe University Cancer Institute, Ankara, Turkey, ${ }^{2}$ Department of Chemistry, Bilkent \\ University, Ankara, Turkey
}

Photodynamic therapy (PDT) has been used as an anti-tumor treatment method for a long time and photosensitizers (PS) can be used in various types of tumors. Originally, light is an effective tool that has been used in the treatment of diseases for ages. The effects of combination of specific dyes with light illumination was demonstrated at the beginning of 20th century and novel PDT approaches have been developed ever since. Main strategies of current studies are to reduce off-target effects and improve pharmacokinetic properties. Given the high interest and vast literature about the topic, approval of PDT as the first drug/ device combination by the FDA should come as no surprise. PDT consists of two stages of treatment, combining light energy with a PS in order to destruct tumor cells after activation by light. In general, PDT has fewer side effects and toxicity than chemotherapy and/or radiotherapy. In addition to the purpose of treatment, several types of PSs can be used for diagnostic purposes for tumors. Such approaches are called photodynamic diagnosis (PDD). In this Review, we provide a general overview of the clinical applications of PDT in cancer, including the diagnostic and therapeutic approaches. Assessment of PDT therapeutic efficacy in the clinic will be discussed, since identifying predictors to determine the response to treatment is crucial. In addition, examples of PDT in various types of tumors will be discussed. Furthermore, combination of PDT with other therapy modalities such as chemotherapy, radiotherapy, surgery and immunotherapy will be emphasized, since such approaches seem to be promising in terms of enhancing effectiveness against tumor. The combination of PDT with other treatments may yield better results than by single treatments. Moreover, the utilization of lower doses in a combination therapy setting may cause less side effects and better results than single therapy. A better understanding of the effectiveness of PDT in a combination setting in the clinic as well as the optimization of such complex multimodal treatments may expand the clinical applications of PDT.

Keywords: PDT-photodynamic therapy, tumor, clinical application, PDD-photodynamic diagnosis, combination (combined) therapy, photoimmunotherapy (PIT) 


\section{INTRODUCTION}

Light is an effective tool that has been used in the treatment of maladies for ages. It was utilized in the treatment of skin diseases in ancient Egypt, India, and China. In addition, photochemotherapy has been used as a treatment method for a long time (Roelandts, 1991). It is known that psoralens were used in India around 1400 BC. In Atharva Veda, which is a collection of Vedic Sanskrit incantations, spells, and hymns, it is stated that Hindus used the psoralens obtained from the seeds of Psoralea corylifolia for the repigmentation of the vithlogenic skin, utilizing the ancient Ayurvedic medicine (Fitzpatrick and Pathak, 1959; Merriam-Webster, 2021). In Ancient Egypt, the Sun represented an important part of the culture and sunlight could be associated with healing properties (Honigsmann, 2013; Grzybowski et al., 2016). The importance of the Sun in Ancient Egypt resulted in its utilization in terms of heliotherapy (Figure 1A) (Goldberg, 1930; McDonagh, 2001). Figure 1 demonstrates phototherapy in Ancient Egypt. The Ebers papyrus (a total length of $20 \mathrm{~m}$ ) represents the largest record of Ancient Egyptian medicine (Hartmann, 2016) and the Papyrus (circa 1500 BC) mentions about vitiligo (Figure 1B) (Ebers, 1875; Bryan, 1930; Millington and Levell, 2007). It is known that Egyptians extracted psoralen from the Ammi majus (bishop's weed) plant growing on the south bank of the Nile and used it in the treatment of leukoderma in the 12th century AD (Daniell and Hill, 1991). Heliotherapy (the use of sunlight or of another source of UV, visible or infrared radiation for therapeutic purposes), which was systematically recorded and described to be used for medicinal purposes by Herodotus in ancient Greece, was applied as an effective treatment method for various diseases (Mitton and Ackroyd, 2008; Honigsmann, 2013; Ceglia and Toni, 2018). In the 18th and 19th centuries, sunlight therapy was used to treat various ailments such as tuberculosis, rickets, scurvy, rheumatism, paralysis, edema, and muscle weakness. However, its utilization in modern medicine started in the 20th century. At the beginning of the 20th century, Danish physician Niels Ryberg Finsen reported that he treated chickenpox under red light by preventing inflammation of the pustules. In the following years, he was awarded with the 1903 Nobel Prize in Physiology or Medicine for "his contribution to the treatment of diseases, especially lupus vulgaris, with concentrated light radiation" (NobelPrize.org; Urbach et al., 1976; Ackroyd et al., 2001).

\section{HISTORY OF PHOTODYNAMIC THERAPY}

The idea of using photodynamic therapy (PDT) as a new treatment strategy was suggested in the early 1900s. In fact, the extraction of hematoporphyrin from dried blood by Schere via removing iron in 1841 is an important milestone for the field of photosensitizers (PSs) (Rasmussen-Taxdal et al., 1955; Kou et al., 2017). A researcher named Oscar Raab observed that paramecia died when incubated under the light with acridine red dyes in Germany. He also observed that those that were not exposed to light remained alive (Hamblin, 2018). In fact, initial observations related with PDT in medicine refer to the inactivation of microorganisms more than a hundred years ago (Raab, 1900; Jori et al., 2006). Thus, the definition of photodynamic action emerged based on this observation. Indeed, Hermann von Tappeiner coined the term "photodynamic reaction", underlining the fact that light played an important role (v. Tappeiner, 1909; Niculescu and Grumezescu, 2021). PDT of infections, which involves reactive oxygen species (ROS) to disrupt and kill microbes, can be useful against bacteria and viruses (Hamblin and Hasan, 2004; Jori, 2006; Oyim et al., 2021; Rapacka-Zdonczyk et al., 2021; Warrier et al., 2021). Due to the World Wars, the evolution of the idea has been delayed for nearly 60 years.

In 1960, generation of new approaches in terms of PDT started with the studies by R. L. Lipson and S. Schwartz at the Mayo Clinic (Dougherty et al., 1998). Lipson et al. reported that malignant diseases could be detected by using an acetic acidsulfuric acid derivative of hematoporphyrin and proper filter systems for activating and viewing the fluorescence (Lipson and Baldes, 1960; Lipson et al., 1961). Schwartz treated hematoporphyrin with acetic acid and sulfuric acid and obtained a porphyrin mixture in order to achieve optimal tumor localization. He termed this mixture as hematoporphyrin derivative $(\mathrm{HpD})$, which contains several porphyrins, monomers as well as dimers and oligomers (Moan, 1986). Lipson et al. used $\mathrm{HpD}$ in order to detect tumors (Dougherty et al., 1998). In 1967, Lipson et al. reported the use of hematoporphyrin derivative in patients for lesions of the esophagus and tracheobronchial tree, cervix and vagina, rectum, breast, tonsil, parotid and intraperitoneal lesions. They proposed that this approach could be helpful in terms of detection and subsequent management of malignant diseases (Lipson et al., 1967). The utilization of $\mathrm{HpD}$ in bladder cancer treatment was reported by Kelly and Snell as one of the first clinical applications in 1976 (Dougherty, 1996; Dougherty et al., 1998; Abrahamse and Hamblin, 2016). In the following years, $\mathrm{HpD}$ was transformed into a drug formulation by Dougherty. Dougherty et al. reported the first clinical case of PDT in a patient with metastatic breast cancer to the skin in 1978 (Dougherty et al., 1998). Furuse et al. conducted phase II clinical trials using Photofrin (porfimer sodium) for early-stage lung cancer between June 1989 and February 1992 (Furuse et al., 1993). In 1993, PDT with Photofrin obtained the first health agency approval in Canada for the treatment of bladder cancer (Usuda et al., 2006). The Food and Drug Administration (FDA) approved Photofrin for esophageal cancer in 1995. In addition, Photofrin was approved for the treatment of early nonsmall cell lung cancer in 1998 (Pass, 1993; Dougherty et al., 1998; Kato, 2004; Huang, 2005).

Indeed, PSs have been used as therapeutic agents for more than a century. The timeline of PDT can be seen in Figure 2. The clinical use of eosin in the treatment of skin cancer may be given as one example of the first PDT applications. Tappeiner and Jesionek aimed to treat skin tumors by using topical eosin (Dolmans et al., 2003; Juarranz et al., 2008). PSs are classified into three generations based on their evolution (Allison et al., 2004; Dave et al., 2012; Freitas and Hamblin, 2016; Baskaran et al., 


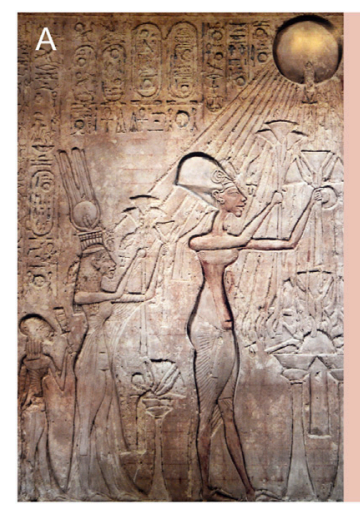

B

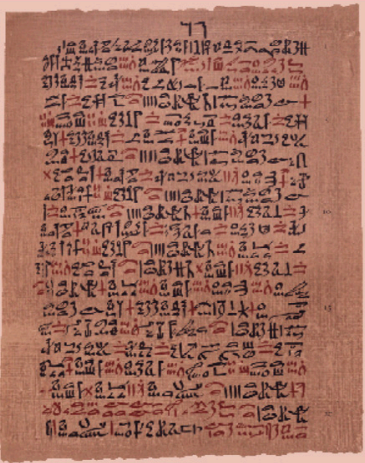

FIGURE 1 | Phototherapy in Ancient Egypt. (A) Veneration of the sun eventually resulted in its utilization as heliotherapy (Shutterstock). (B) The Ebers Papyrus mentioned the Pharaoh's utilization of phototherapy utilizing various plants (Ebers papyrus, University of Leipzig, Germany, https://commons.wikimedia.org, public domain) (Abdel-kader, 2016).

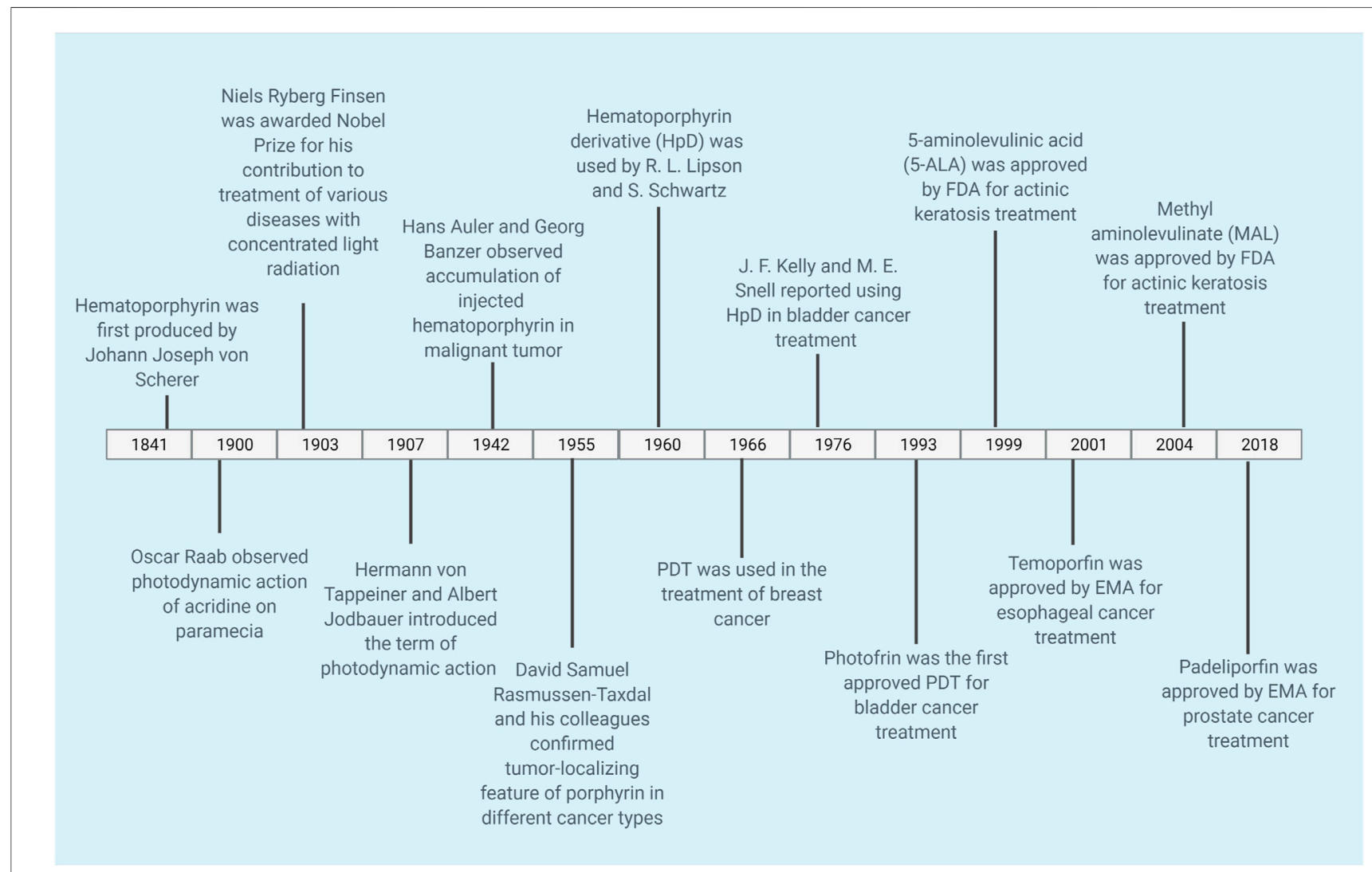

FIGURE 2 | Timeline of PDT. The timeline shows selected applications of PDT for cancer. PDT, photodynamic therapy.

2018). Table 1 demonstrates examples of first, second and third generation PSs.

Naturally occurring porphyrins and their derivatives constitute the first generation of PSs (Peterson et al., 1992; Schmidt-Erfurth et al., 1998; Clarke et al., 2006; Qiu et al., 2017). Figure 3 demonstrates examples of first and second generation PSs. Hematoporphyrin, which was used in cancer treatment in the 1950s, and Photofrin, which was approved by the FDA in the treatment of various cancers such as lung, esophagus, and cervix, are among the examples of first generation PSs. Indeed, most first generation PSs were developed around 1970s (Freitas and Hamblin, 2016). The first generation PSs were used in early clinical trials of PDT (Spikes, 1990; Kou et al., 2017). Even though first generation PSs were thought to 
TABLE 1 | Selected examples of first, second and third generation PSs. PS, photosensitizer.

First generation PSs

Porphyrin

Hematoporphyrin

\section{Second generation PSs}

Benzoporphyrin

5-Aminolevulinic acid

Protoporphyrin IX

Phthalocyanine

Chlorin

\section{Third generation PSs}

Antibody conjugates

Encapsulated agents into carriers (e.g. liposomes, micelles, nanoparticles)

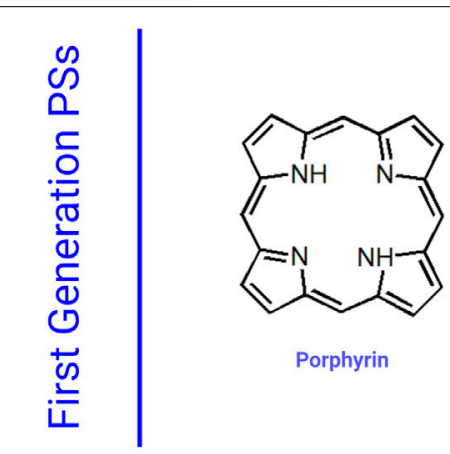

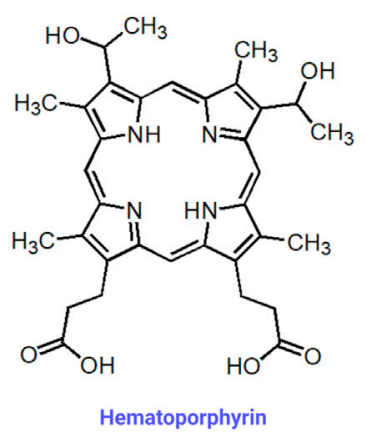
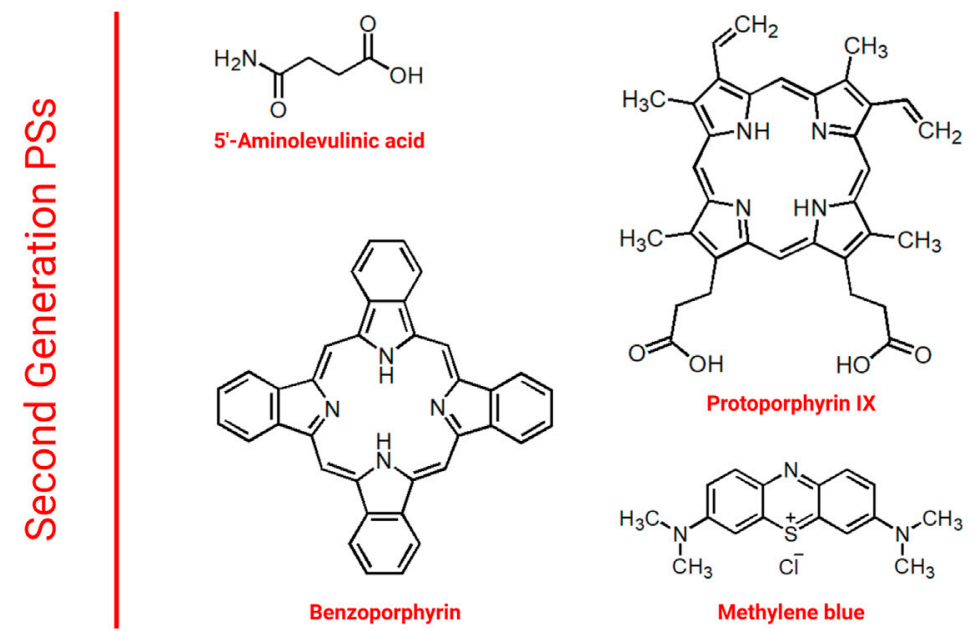<smiles>Cc1cc2nc3ccc(=[N+](C)C)cc-3sc2cc1N</smiles>
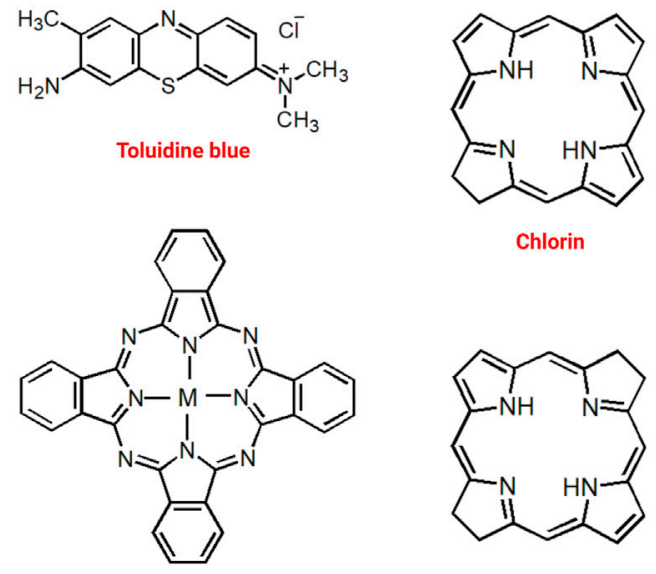

Chlorin

Phthalocyanine

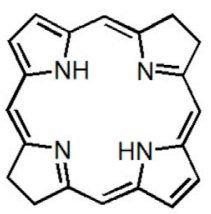

Bacteriochlorin

FIGURE 3 | Selected Examples of First and Second Generation PSs. PS, photosensitizer.

demonstrate favorable photodynamic activity, they bear important disadvantages such as dark cytotoxicity, cutaneous phototoxicity and low absorption bands at red wavelengths as well as issues related with hydrophobicity.

Second generation PSs were developed in order to overcome the problems associated with first generation PSs (Figure 3) (Gomer, 1991). Second generation PSs include 5aminolevulinic acid, benzoporphyrin, chlorin and phthalocyanine (Allison et al., 2004; Bazylinska et al., 2012; Duchi et al., 2013). In general, second generation PSs are activated with wavelengths above $650 \mathrm{~nm}$ and they demonstrate less phototoxicity (Freitas and Hamblin, 2016). In addition, the clearance of second generation PSs from normal tissues is quicker than that of porphyrins (Bazylinska et al., 2012).
Second generation PSs also demonstrate high singlet oxygen quantum yield and high solubility in water. Although they can be used in various types of cancer, they might still cause tissue damage due to high toxicity as well as demonstrating low stability. In order to achieve more accurate targeting, various chemical modifications can be made (Nishiyama et al., 2009; Senge, 2012). Such approaches resulted in the generation next generation PSs. Indeed development of specific carriers for the delivery of PSs aiming to cause less phototoxicity in normal tissues may help to improve PDT outcomes.

Third generation PSs utilize available drugs by modifying them (Allison et al., 2004; Josefsen and Boyle, 2008; MfouoTynga et al., 2021). Third generation PSs usually consist of second generation PSs that were modified with specific agents (e.g., 


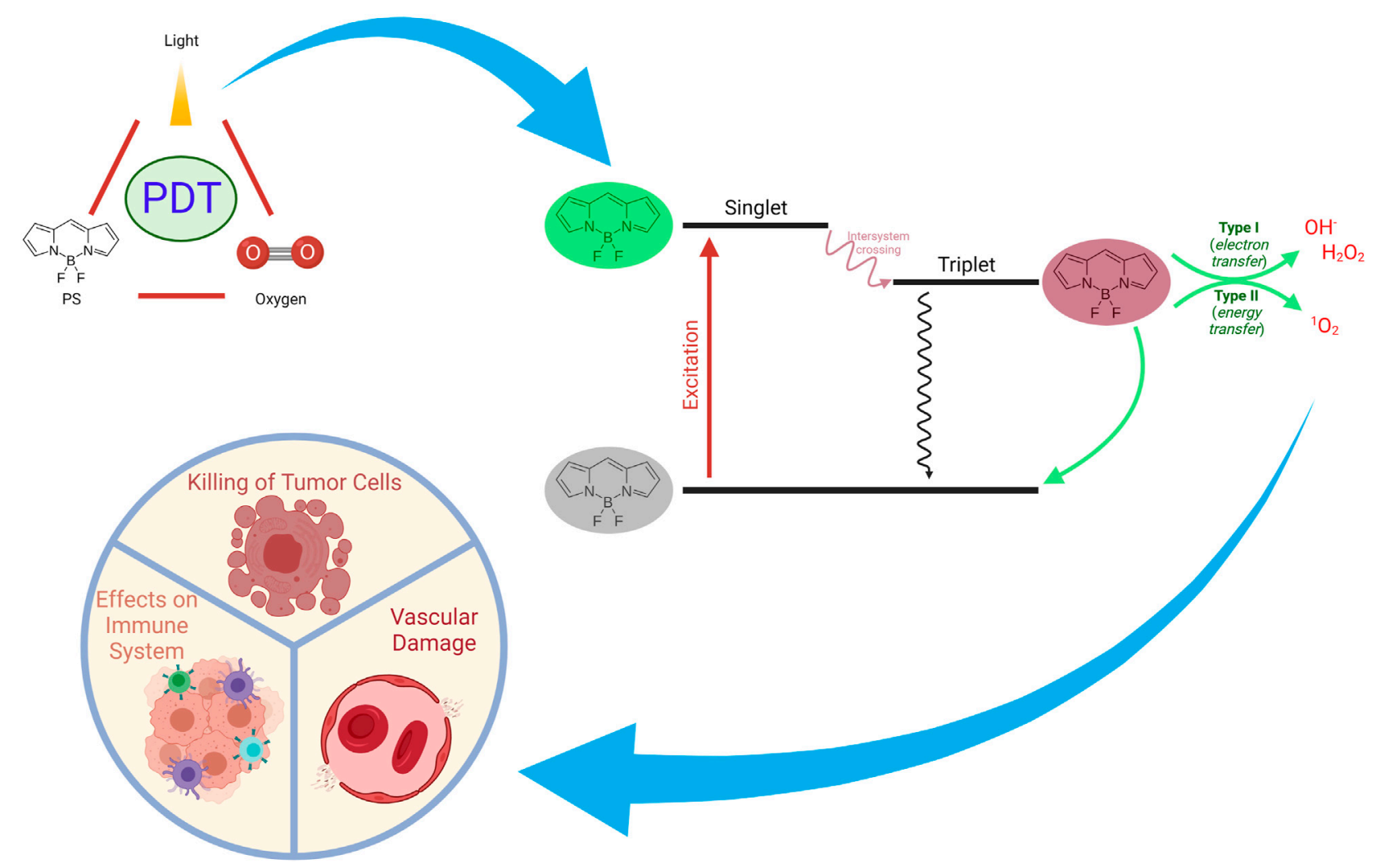

FIGURE 4 | Mechanisms of Action of PDT on Tumors. PDT can exert a plethora of actions such as inducing immune responses, direct killing of tumor cells, and damaging vascular structures.

antibody conjugation) or were encapsulated into carriers in order to increase the accumulation at the target area (Moser, 1998; Hudson et al., 2005; Staneloudi et al., 2007; O’Connor et al., 2009; Narumi et al., 2016; Nishie et al., 2016; Mfouo-Tynga et al., 2021). Indeed, current studies aim to develop third generation PSs in order to decrease off-target effects and to improve pharmacokinetic properties. An important concept in terms of third generation PSs is the utilization of molecular carriers such as nanoparticles. Such carriers are mainly utilized in order to deliver various PSs to the cells, given the probable poor water-solubility of the PSs (Chilakamarthi and Giribabu, 2017; Kwiatkowski et al., 2018). Various carrier molecules are developed in order to increase the effectiveness of PDT such as liposome, micelle, quantum dot, dendrimer, polymer; magnetic gold, and carbonbased nanoparticles (Abrahamse et al., 2017). For instance, chlorin E6 was incorporated into nanoparticles via formation of ion complexes in order to increase absorption by the tumor (Lee et al., 2013).

Encapsulation of drugs into delivery systems has been as area of extensive research over the last years (Rout et al., 2017; Barras et al., 2018; Fasiku et al., 2021; Karges et al., 2021; Mitchell et al., 2021). Although bioconjugation and encapsulation with targeting moieties seem to be critical approaches in order to develop more effective and specific PSs, it should also be borne in mind that an ideal PS should achieve high quantum yield, display long-wave absorption, cause low dark toxicity, demonstrate favorable pharmacokinetic properties, have high purity and stability (Wöhrle et al., 1998). Furthermore, becoming activated at different wavelengths and having amphiphilic properties can also be considered among the favorable features for PSs (Allison, 2014). Last but not least, it should be kept in mind that classifying drugs into generations does not necessarily mean that all newer drugs are better that the older ones (Allison et al., 2004). Future clinical studies comparing the effectiveness as well as adverse effects of different PSs in large cohorts of patients will pave the way for the development of more potent PSs.

\section{CLINICAL APPLICATIONS OF PHOTODYNAMIC THERAPY IN CANCER}

PDT is an approach which mainly requires three components, i.e. a photosensitizer, light and oxygen (Moore et al., 2009; Allison and Moghissi, 2013b; Dos Santos et al., 2019). Mechanisms of action of PDT on tumors can be seen in Figure 4. In general, PSs are in inactive state unless they are exposed to specific light. Moreover, photodynamic activity is dependent on the presence of oxygen. The light activated PS generates ROS, which mainly result in the effector functions (e.g., killing of tumor cells) (Castano et al., 2006; Avendaño and Menéndez, 2015). PDT 


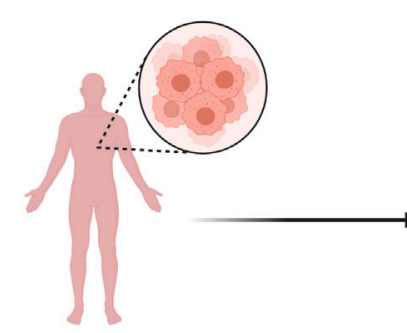

Cancer Patient

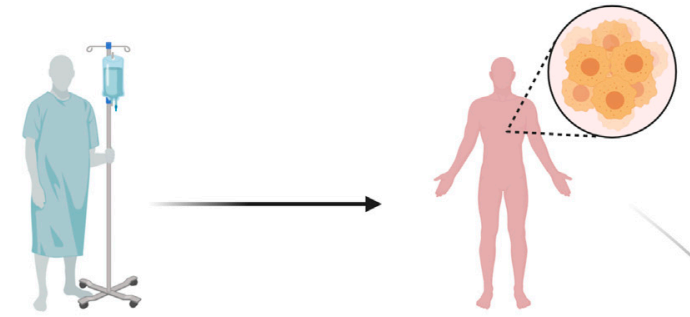

Administration of PS
Destruction of Tumor

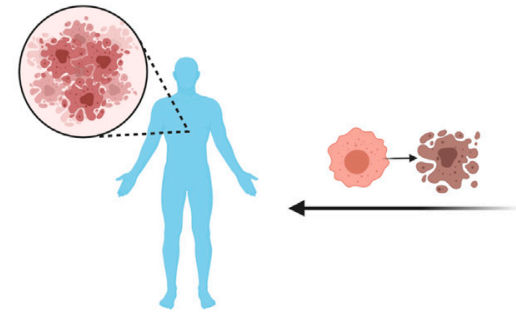

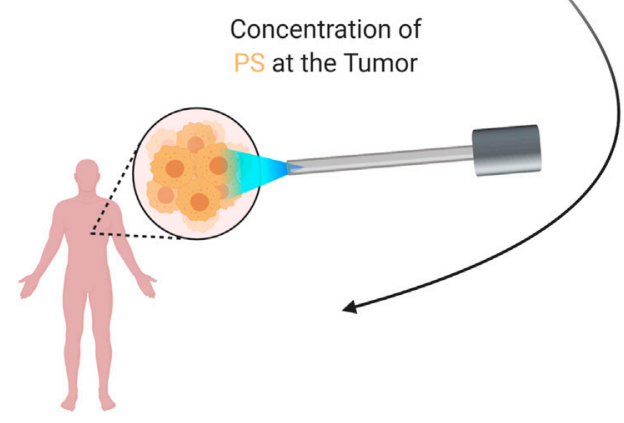

Activation of PS by Light

FIGURE 5 | Therapeutic Application of PDT. The patient is administered with the PS, which concentrates at the tumor. The PS is then activated by a specific light, which generates reactive oxygen species; resulting in tumor destruction. PDT, photodynamic therapy; PS, photosensitizer.

comprises two stages of clinical treatment, combining light energy with a PS in order to destroy tumor cells after activation by light (Figure $\mathbf{5}$ demonstrates therapeutic application of PDT). Several side effects and limitations can restrict the use of some PDT agents (Yoo and Ha, 2012). Problems such as lack of selectivity, poor water-solubility, possible toxic effects on healthy tissues, skin photosensitivity that is associated with certain PSs may prevent the clinical applications of various PDT approaches. Many research groups have undertaken the task to overcome such issues and several promising targeted approaches have been reported over the last years (Turan et al., 2016; Karaman et al., 2019; Ayan et al., 2020). Novel innovative strategies aim to increase the delivery of PSs to tumor tissues, to augment specificity and to increase efficiency (Bugaj, 2011). Further clinical studies and proof of principle approaches will pave the way for better PDT modalities.

\section{Clinical Efficacy of Photodynamic Therapy in Cancer}

PDT was the first drug/device combination approved by the FDA (Agostinis et al., 2011). Various PSs have been commercialized or used in clinical trials up to date (Agostinis et al., 2011; Zhao et al., 2021). One of the most frequently used PSs in the clinic is Photofrin (porfimer sodium). The first approval of PDT with Photofrin was obtained in Canada in 1993 for the treatment of bladder cancer (Usuda et al., 2006). In Netherlands and France, Photofrin was approved for the treatment of advanced lung cancers, whereas it was approved in Germany for the treatment of early stage lung cancer (Usuda et al., 2006). In summary, Photofrin has been approved by the FDA for three indications, i.e. palliation of patients with esophageal cancer; treatment of microinvasive endobronchial non-small-cell lung cancer (NSCLC) and reduction of obstruction and palliation of symptoms in patients with completely or partially obstructing endobronchial NSCLC; and ablation of high-grade dysplasia in Barrett's esophagus (Pinnacle Biolgs, 2020). Selected PSs approved by the FDA can be seen in Table 2. It is activated by red light from a laser. Aminolevulinic acid (ALA) has been approved by the FDA for the indication of topical treatment of minimally to moderately thick actinic keratoses of the face or scalp, or actinic keratoses of the upper extremities (in summary) (Table 2) (DUSA, 2018). In addition, oral solution of ALA has been approved by the FDA as an optical imaging agent indicated in patients with glioma as an adjunct for the visualization of malignant tissue during surgery (in summary) (Table 2) (NXDC, 2018). Methyl aminolevulinate has been approved by the FDA for the indication of treatment of thin and moderately thick, nonhyperkeratotic, non-pigmented actinic keratoses of the face and scalp in immunocompetent patients (in summary) (Table 2) (Galderma Labs LP, 2012). Hexaminolevulinate has been approved by the FDA as an optical imaging agent indicated for use in the cystoscopic detection of carcinoma of the bladder (in summary) (Table 2) (Photocure ASA, 2018). Indeed, several preclinical and clinical studies are ongoing in order to develop new PSs and PDT approaches.

\section{Therapeutic Applications of Photodynamic Therapy}

Photodynamic therapy is indeed a treatment method used to treat various diseases utilizing the photosensitizer's photophysical and 
TABLE 2 | Selected PSs approved by the FDA. PS, photosensitizer, NSCLC, non-small-cell lung cancer.

Name of PS

Porfimer sodium

Aminolevulinic acid

Methyl aminolevulinate

Hexaminolevulinate

\section{Indications and usage}

- Palliation of patients with esophageal cancer

- Treatment of microinvasive endobronchial NSCLC and reduction of obstruction and palliation of symptoms in patients with completely or partially obstructing endobronchial NSCLC

- Ablation of high-grade dysplasia in Barrett's esophagus

- Topical treatment of minimally to moderately thick actinic keratoses of the face or scalp, or actinic keratoses of the upper extremities

- (Oral solution) as an optical imaging agent indicated in patients with glioma as an adjunct for the visualization of malignant tissue during surgery

- Treatment of thin and moderately thick, non-hyperkeratotic, non-pigmented actinic keratoses of the face and scalp in immunocompetent patients

- An optical imaging agent indicated for use in the cystoscopic detection of carcinoma of the bladder

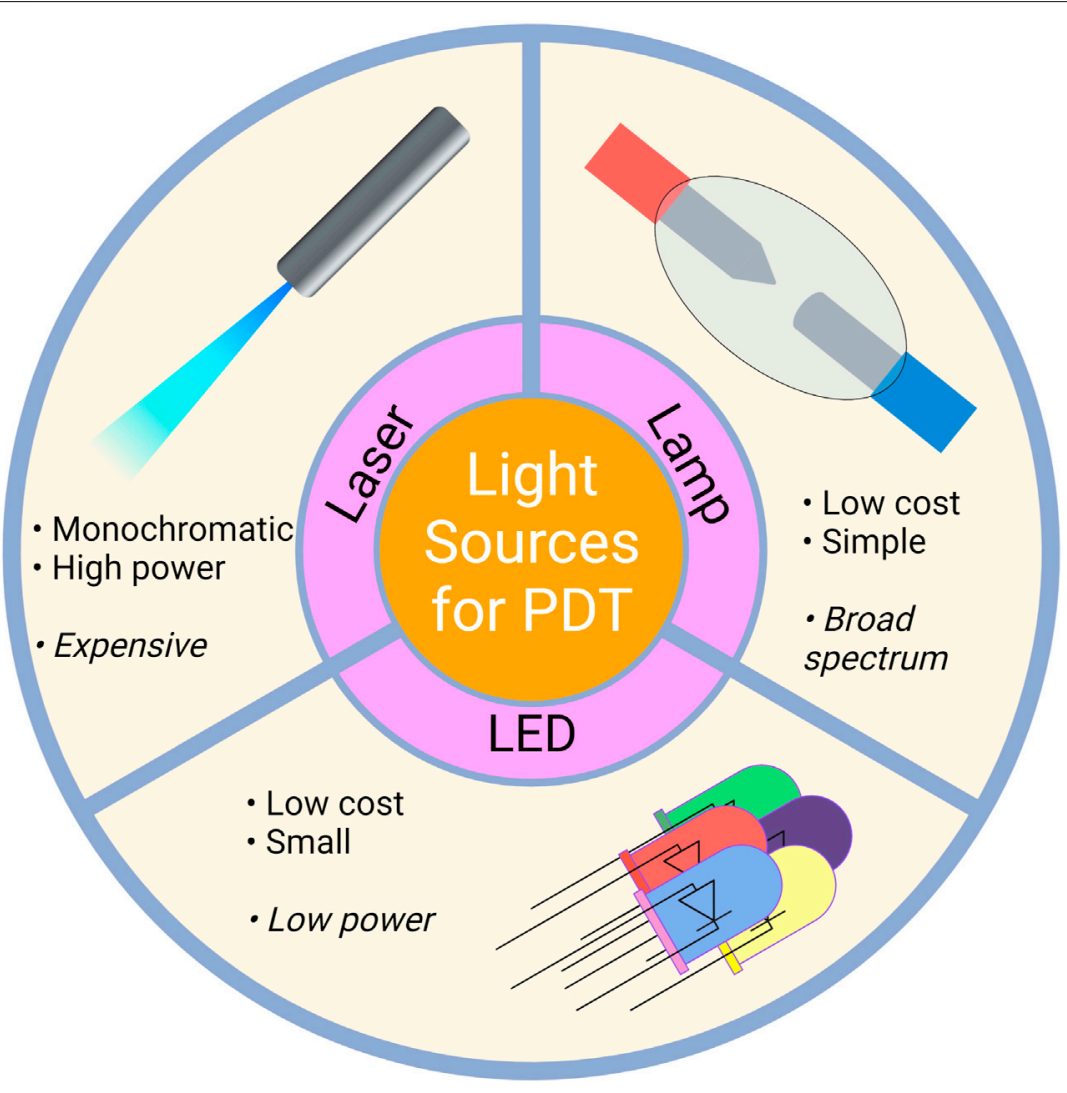

FIGURE 6 | Light Sources Utilized in PDT. Laser, lamp and LED sources can be used for PDT applications. LED, light emitting diodes.

chemical properties. Mechanistically, photodynamic treatment consists of two steps. The first step is the excitation of PS, which is induced by light. Two groups of light sources can be utilized in terms of the photoexcitation stage of PDT, i.e., laser and nonlaser. Light sources utilized in PDT can be seen in Figure 6. Laser light sources include Argon Lasers and Argon-pumped Dye Lasers, Metal Vapor-pumped Dye Lasers, Solid State Lasers, Optical Parametric Oscillators, and Diode Lasers. On the other hand, Tungsten Filament Quartz Halogen Lamps, Xenon Arc Lamps, Metal Halide Lamps, Phosphor-coated Sodium Lamps, and Fluorescent Lamps are among the non-laser light sources. In addition to these sources, Light Emitting Diodes (LED) and Femtosecond Solid State Lasers may also be utilized (Brancaleon and Moseley, 2002).

The reaction of the photochemically excited PS with molecular oxygen constitutes the second step of PDT. Upon excitation by specific light, one of the electrons of the PS in the ground state $\left(\mathrm{S}_{0}\right)$, which has two electrons in opposite spins in a molecular orbit involving lower energy, is excited towards the molecular orbit involving higher energy (singlet state $=S_{1}$ ) without changing its spin. According to the Jablonski energy diagram, PS with high energy orbit or singlet state can transform to the 
TABLE 3 | Selected recent active PDT studies for malignant diseases obtained from ClinicalTrials.gov database.

\begin{tabular}{|c|c|c|c|c|c|c|c|}
\hline Title & Status & Cancer type & Photosensitizer & $\begin{array}{c}\text { Excitation } \\
\text { wavelength }\end{array}$ & Phase & Start date & $\begin{array}{c}\text { ClinicalTrials.gov } \\
\text { identifier }\end{array}$ \\
\hline $\begin{array}{l}\text { Study to evaluate the safety } \\
\text { and efficacy of BF-200 ALA } \\
\left(\text { Ameluz }^{\circledR} \text { ) and BF- }\right. \\
\text { RhodoLED }{ }^{\circledast} \text { in the } \\
\text { treatment of superficial } \\
\text { basal cell carcinoma } \\
\text { (sBCC) with photodynamic } \\
\text { therapy (PDT) }\end{array}$ & Recruiting & Basal cell carcinoma & ALA-PDT (Ameluz ${ }^{\circledR}$ _PDT) & $635 \mathrm{~nm}$ & Phase 3 & $\begin{array}{l}\text { September } \\
25,2018\end{array}$ & NCT03573401 \\
\hline $\begin{array}{l}\text { Use of jet-injection in } \\
\text { photodynamic therapy for } \\
\text { basal cell carcinoma }\end{array}$ & Recruiting & Basal cell carcinoma & $\begin{array}{l}\text { Jet-injection (AirGent2.0) of } \\
\text { ALA (levulan kerastick) }\end{array}$ & 400-450 nm & Phase 2 & $\begin{array}{l}\text { September } \\
9,2020\end{array}$ & NCT04552990 \\
\hline $\begin{array}{l}\text { Intravesical photodynamic } \\
\text { therapy (PDT) in BCG } \\
\text { refractory/Intolerant non- } \\
\text { muscle invasive bladder } \\
\text { cancer (NMIBC) patients }\end{array}$ & Recruiting & Bladder cancer & $\begin{array}{l}\text { TLD-1433 (Ru(II) polypyridyl } \\
\text { complex) }\end{array}$ & $520-540$ nm & Phase 2 & $\begin{array}{l}\text { August 30, } \\
2019\end{array}$ & NCT03945162 \\
\hline $\begin{array}{l}\mathrm{PCl} \text { treatment/Gemcitabine } \\
\& \text { chemotherapy vs } \\
\text { chemotherapy alone in } \\
\text { patients with inoperable } \\
\text { extrahepatic bile duct } \\
\text { cancer }\end{array}$ & Recruiting & Cholangiocarcinoma & Fimaporfin & $435 \mathrm{~nm}$ & Phase 2 & $\begin{array}{l}\text { May 23, } \\
2019\end{array}$ & NCT04099888 \\
\hline $\begin{array}{l}\text { A trial of a new type of } \\
\text { photodynamic therapy } \\
\text { (VTP) in the treatment of } \\
\text { patients with cancer of the } \\
\text { esophagus who have } \\
\text { trouble swallowing }\end{array}$ & Recruiting & $\begin{array}{l}\text { Esophagogastric } \\
\text { cancer }\end{array}$ & $\begin{array}{l}\text { WST11-mediated vascular- } \\
\text { targeted photodynamic } \\
\text { therapy (VTP) }\end{array}$ & $753 \mathrm{~nm}$ & Phase 1 & $\begin{array}{l}\text { April 26, } \\
2017\end{array}$ & NCT03133650 \\
\hline $\begin{array}{l}\text { Intraoperative } \\
\text { photodynamic therapy of } \\
\text { glioblastoma }\end{array}$ & $\begin{array}{l}\text { Active, not } \\
\text { recruiting }\end{array}$ & Glioblastoma & $\begin{array}{l}\text { Gliolan }^{\circledR} \text { (5-ALA- PpIX } \\
\text { (protoporhyrin IX)) }\end{array}$ & $400-410 \mathrm{~nm}$ & $\begin{array}{l}\text { Not } \\
\text { applicable }\end{array}$ & May 5, 2017 & NCT03048240 \\
\hline $\begin{array}{l}\text { Stereotactical } \\
\text { photodynamic therapy with } \\
5 \text {-aminolevulinic acid } \\
\left(\text { Gliolan }^{\oplus} \text { ) in recurrent }\right. \\
\text { glioblastoma }\end{array}$ & Recruiting & Glioblastoma & $\begin{array}{l}\text { Gliolan }^{\circledast}(5-A L A-P p I X \\
\text { (protoporhyrin IX)) }\end{array}$ & $400-410 \mathrm{~nm}$ & Phase 2 & March 2021 & NCT04469699 \\
\hline $\begin{array}{l}\text { Porfimer sodium interstitial } \\
\text { photodynamic therapy with } \\
\text { or without standard of care } \\
\text { chemotherapy in treating } \\
\text { patients with locally } \\
\text { advanced or recurrent } \\
\text { head and neck cancer }\end{array}$ & Recruiting & $\begin{array}{l}\text { Head and neck } \\
\text { carcinoma }\end{array}$ & Porfimer sodium (Photofrin ${ }^{\circledR}$ ) & $630 \mathrm{~nm}$ & Phase 2 & $\begin{array}{l}\text { January 16, } \\
2019\end{array}$ & NCT03727061 \\
\hline $\begin{array}{l}\text { Endobronchial ultrasound } \\
\text { guided interstitial } \\
\text { photodynamic therapy in } \\
\text { treating patients with locally } \\
\text { advanced lung cancer }\end{array}$ & Recruiting & Lung carcinoma & Porfimer sodium (Photofrin ${ }^{\circledR}$ ) & $630 \mathrm{~nm}$ & $\begin{array}{l}\text { Early } \\
\text { phase } 1\end{array}$ & $\begin{array}{l}\text { February 4, } \\
2020\end{array}$ & NCT03735095 \\
\hline $\begin{array}{l}\text { Photodynamic therapy for } \\
\text { prevention of } \\
\text { nonmelanoma skin cancer } \\
\text { in organ transplant } \\
\text { recipients }\end{array}$ & Recruiting & $\begin{array}{l}\text { Nonmelanoma skin } \\
\text { cancers }\end{array}$ & ALA (levulan kerastick) & $400-450 \mathrm{~nm}$ & $\begin{array}{l}\text { Not } \\
\text { applicable }\end{array}$ & $\begin{array}{l}\text { February } \\
2016\end{array}$ & NCT02751151 \\
\hline $\begin{array}{l}\text { Photodynamic therapy with } \\
\text { HPPH compared to } \\
\text { standard of care surgery in } \\
\text { treating patients with oral } \\
\text { cavity cancer }\end{array}$ & $\begin{array}{l}\text { Active, not } \\
\text { recruiting }\end{array}$ & $\begin{array}{l}\text { Oral cavity squamous } \\
\text { cell carcinoma }\end{array}$ & $\begin{array}{l}\text { HPPH (photochlor) (2-1 } \\
\text { [heyloxyethyl]-2- } \\
\text { devinylpyropheophorbide-a) }\end{array}$ & $665 \mathrm{~nm}$ & Phase 2 & $\begin{array}{l}\text { March 30, } \\
2017\end{array}$ & NCT03090412 \\
\hline $\begin{array}{l}\text { Ultrasound-guided } \\
\text { verteporfin photodynamic } \\
\text { therapy for the treatment of } \\
\text { unresectable solid } \\
\text { pancreatic tumors or }\end{array}$ & Recruiting & Pancreatic carcinoma & Verteporfin & $690 \mathrm{~nm}$ & Phase 2 & $\begin{array}{l}\text { December 6, } \\
2016\end{array}$ & NCT03033225 \\
\hline
\end{tabular}

(Continued on following page) 
TABLE 3 | (Continued) Selected recent active PDT studies for malignant diseases obtained from ClinicalTrials.gov database.

\begin{tabular}{|c|c|c|c|c|c|c|c|}
\hline Title & Status & Cancer type & Photosensitizer & $\begin{array}{c}\text { Excitation } \\
\text { wavelength }\end{array}$ & Phase & Start date & $\begin{array}{c}\text { ClinicalTrials.gov } \\
\text { identifier }\end{array}$ \\
\hline \multicolumn{8}{|l|}{$\begin{array}{l}\text { advanced pancreatic } \\
\text { cancer, VERTPAC-02 } \\
\text { study }\end{array}$} \\
\hline $\begin{array}{l}\text { Study of the efficacy, safety } \\
\text { and quality of life after } \\
\text { TOOKAD }{ }^{\circledast} \text { soluble (VTP) for } \\
\text { intermediate risk prostate } \\
\text { cancer }\end{array}$ & $\begin{array}{l}\text { Active, not } \\
\text { recruiting }\end{array}$ & Prostate cancer & TOOKAD ${ }^{\circledast}$ soluble VTP & $753 \mathrm{~nm}$ & Phase 2 & $\begin{array}{l}\text { October 2, } \\
2017\end{array}$ & NCT03315754 \\
\hline $\begin{array}{l}\text { Study of erectile } \\
\text { dysfunction, urinary } \\
\text { incontinence and related } \\
\text { QoL after TOOKAD }{ }^{\circledR} \text { VTP } \\
\text { for low risk prostate cancer }\end{array}$ & $\begin{array}{l}\text { Active, not } \\
\text { recruiting }\end{array}$ & Prostate cancer & TOOKAD ${ }^{\oplus}$ soluble VTP & $753 \mathrm{~nm}$ & Phase 4 & $\begin{array}{l}\text { January 21, } \\
2019\end{array}$ & NCT03849365 \\
\hline $\begin{array}{l}\text { Clinical study to assess the } \\
\text { safety and adequacy of } \\
\text { effectiveness of the } \\
\text { SpectraCure P18 system }\end{array}$ & Recruiting & Prostate cancer & Verteporfin & $690 \mathrm{~nm}$ & Phase 1 & $\begin{array}{l}\text { March 21, } \\
2017\end{array}$ & NCT03067051 \\
\hline $\begin{array}{l}\text { HS-201, an } \\
\text { HSP90 inhibitor-linked } \\
\text { verteporfin for detection of } \\
\text { solid malignancies }\end{array}$ & Recruiting & Solid tumor & $\begin{array}{l}\text { HS-201 (verteporfin-tethered } \\
\text { HSP90 inhibitor) }\end{array}$ & $690 \mathrm{~nm}$ & Phase 1 & $\begin{array}{l}\text { July 15, } \\
2020\end{array}$ & NCT03906643 \\
\hline $\begin{array}{l}\text { Phase I study in advanced } \\
\text { malignancies }\end{array}$ & Recruiting & Solid tumor & ALA (5-aminolevulinic acid) & $635 \mathrm{~nm}$ & Phase 1 & $\begin{array}{l}\text { July } 23 \text {, } \\
2020\end{array}$ & NCT04381806 \\
\hline $\begin{array}{l}\text { Treatment of tumors in the } \\
\text { urinary collecting system of } \\
\text { the kidney or ureter using a } \\
\text { light activated drug } \\
\text { (WST11) }\end{array}$ & Recruiting & $\begin{array}{l}\text { Upper tract urothelial } \\
\text { carcinoma }\end{array}$ & WST11 & $753 \mathrm{~nm}$ & Phase 1 & $\begin{array}{l}\text { August 1, } \\
2018\end{array}$ & NCT03617003 \\
\hline
\end{tabular}

ground state in a short time by fluorescent radiation (emission) or heat releasing (internal conversion $=$ IC) (Figure 4). By performing intersystem crossing (ISC) to the triplet state, it may transform into a long-lasting form. The triplet state's transformation occurs in parallel with the transformation in the singlet state by phosphorescence radiation (emission) or heat releasing (IC). When PDT is applied in biological systems, PS reaches a high-energy triplet state as a result of the absorption of light. Then, PS reacts with cellular substrates (biomolecules) (Type I reaction) and ROS are generated. On the other hand, energy transfer to molecular oxygen (excitation energy transfer, EET) leads to the conversion of oxygen to singlet oxygen (Type II reaction) (Figure 4). In both cases, the reaction of the generated molecules with vital cellular components such as lipids, proteins, and nucleic acids can result in toxicity to the organism (Chilakamarthi and Giribabu, 2017; Kwiatkowski et al., 2018).

Depending on the type of PDT and its ROS production efficiency, PDT may affect cellular antioxidants and heat shock proteins as well as anti-tumor immune responses. Transformation of ROS into nontoxic molecules is catalyzed by antioxidant enzymes inside the cell, such as superoxide dismutase, catalase and glutathione peroxidase. Antioxidant enzymes take active part in the breakdown of superoxide anions and hydrogen peroxides that accumulate in the cell. Additionally, small molecules such as glutathione, vitamins E and $\mathrm{C}$ also help to ensure intracellular control of ROS. It has been reported that cancer cells generate more ROS than normal cells. Therefore, cancer cells require a robust antioxidant system in order to be able to survive. It was reported that the cytotoxic effects of PDT are enhanced when antioxidant enzymes or glutathione synthesis mechanisms are targeted during PDT (Ayan et al., 2020). It was demonstrated that L-buthionine sulfoximine, which is a glutathione synthesis inhibitor, boosts PDT effects. Similarly, targeting cyclooxygenase, which regulates inflammation and homeostasis, and heat shock proteins, which are activated by oxidative stress and have an essential functional role in protein folding, can increase the effectiveness of PDT (Kimani et al., 2012; Dabrowski and Arnaut, 2015). PDT might achieve direct killing of tumor cells by generating ROS or singlet oxygen in the tumor cells. Moreover, it can also result in tumor associated vascular damage and; hence, tumor infarction (Castano et al., 2005). Finally yet importantly, PDT may also induce enhanced immune responses against the tumor (Dolmans et al., 2003).

PDT generally demonstrates fewer side effects and less toxicity than chemotherapy and/or radiotherapy used in conventional cancer treatment (Li X. et al., 2020). Indeed, PDT has been used in cancer treatment for some time. More than two hundred clinical trials have been conducted until recently. In addition, there are currently numerous ongoing studies. Selected studies can be seen in Table 3. In a porfimer sodium based PDT study conducted with 1,440 patients diagnosed with basal cell carcinoma, which is the most common skin cancer type, PDT was reported to 
demonstrate an initial complete response rate of $92 \%$, with a recurrence rate of less than $10 \%$ at 4 years (Zeitouni et al., 2001; Garcia-Zuazaga et al., 2005; Agostinis et al., 2011). In addition to cancer, PDT may also be used in other diseases such as those of the skin and the eye (Wilson and Patterson, 2008). It is also an effective treatment option for Barrett's esophagus, unresectable cholangiocarcinoma and non-melanoma skin lesions.

\section{Targeting Strategies in Photodynamic Therapy}

Tumor-targeted PDT can be divided into two groups, i.e., passive targeting and active targeting (Pernot et al., 2013). Passive targeting takes advantage of physiological and morphological differences between normal and tumor tissues to achieve tumor-selective targeting as well as PS accumulation. The uncontrolled proliferation of tumor cells results in vessels with irregular structure. Tumor vessels are usually leaky and tortuous with irregular branching in contrast to normal tissues (Carmeliet and Jain, 2011). Due to the heterogeneous structure of the vessels as well as the basement membrane and irregular endothelial cells, most drugs that are administered accumulate in tumor tissues. In addition, components of the extracellular matrix (ECM) such as collagen, elastin and hyaluronan are generally expressed more in tumor tissues than their normal counterparts. Although such conditions can be regarded as an obstacle for the transfer of some drugs, it is known that porphyrin derivatives interact with collagen. Semi-specific passive targeting may be achieved via using such characteristics of the tumor.

Various surface receptors are expressed more by tumor cells than normal cells. Such receptors can be utilized in terms of active targeting (Schmitt and Juillerat-Jeanneret, 2012). For instance, HER2 is overexpressed in $15-30 \%$ of invasive breast cancers (Burstein, 2005; Iqbal and Iqbal, 2014). HER2, which is also known as ErbB2, is a member of the HER receptor family (Yu et al., 2018). Breast cancers may bear up to $25-50$ copies of the HER2 gene, resulting in an estimated number of two million receptors expressed at the tumor cell surface (Kallioniemi et al., 1992), while a normal cell surface has much less HER2 receptors. Such a difference in receptor expression underlies an active targeting strategy, which takes advantage of the combination of PDT with trastuzumab. Indeed, trastuzumab, which is a humanized anti-HER2 antibody, is the first HER2-targeted therapeutic monoclonal antibody approved by the FDA in 1998 for the therapy of metastatic HER2 ${ }^{+}$breast cancer (Rossi et al., 2016; Shu et al., 2020). In addition to targeting receptors with specific monoclonal antibodies, conjugation of PSs with specific ligands that bind to the receptors is also a promising approach. Mannose conjugated PSs (Zhang et al., 2017) to target mannose receptors that may be overexpressed in breast cancer cells, EGF conjugated PSs for targeting EGFR receptors (Kuo et al., 2010), cannabinoid CB2 receptor (a G-protein coupled receptor)/translocator protein (a mitochondria membrane receptor) targeted PSs (Yang et al., 2017; Zhang J. et al., 2018) can also be utilized for active targeting strategies in breast cancer (Savellano et al., 2005; Eccles, 2011; Shirasu et al., 2013).

It is widely known that the tumor milieu contains various types of cells in addition to tumor cells (e.g., immune cells and fibroblasts) (Gunaydin et al., 2015; Gok Yavuz et al., 2019; Jin and
Jin, 2020; Gunaydin, 2021). The efficacy of PDT may be affected by the components of the complex tumor microenvironment. Thus, recent approaches incorporating nanotechnology strategies in order to augment the effects of PDT via remodeling the tumor microenvironment (e.g., reshaping tumor vessels, ECM, and antitumor immune responses) are exciting (Liang et al., 2020; Sorrin et al., 2020). Moreover, increased selectivity for cancer cells may be achieved by altering PSs with bioresponsive elements. Targeting overexpressed enzymes in tumor cells in contrast to normal cells is an encouraging approach in order to generate ROS specifically in tumor cells (Gunaydin et al., 2021).

In normal healthy cells, glucose taken into the cell under normoxic conditions is broken down into pyruvate in the cytosol. The pyruvate is transported to the mitochondria, where it is oxidized by pyruvate dehydrogenase. This is followed by the citric acid cycle. Under anoxic or hypoxic (low partial oxygen pressure) conditions, the reduction of pyruvate to lactate is catalyzed by lactate dehydrogenase. Pyruvate cannot be transported to the mitochondria, with the inhibition of pyruvate dehydrogenase by pyruvate dehydrogenase kinase (PDK). Indeed, hypoxia is a common feature of the tumor microenvironment (Gunaydin and Gedik, 2019). While approximately 38 ATP molecules are generated as a result of each cycle in healthy aerobic cells, 2 ATP molecules are generated as a result of each cycle in the cancer cells. Cancer cells maintain energy production by increasing the expression of glucose transporter (GLUT) on the cell surface and; thus, glucose uptake into the cell. It is known that cancer cells prefer aerobic glycolysis under normoxic (typical oxygenated environment) conditions. This mechanism is called the Warburg effect (Gatenby and Gillies, 2004; DeBerardinis et al., 2008; Gogvadze et al., 2008; Vander Heiden et al., 2009). Thus, novel PDT approaches can also be based on the Warburg effect. Kataoka et al. reported developing a third generation PDT by synthesizing a sugar conjugated chlorin PS, with enhanced cancer cell selective accumulation, since tumors cells consume higher levels of glucose than normal cells due to the Warburg effect (Kataoka et al., 2017). They reported that glucose conjugated chlorin based PDT demonstrated more potent anti-tumor effects than second generation talaporfin mediated PDT. Moreover, PDT with glucose conjugated chlorin was found to induce immunogenic cell death (Kataoka et al., 2017). In another study, Gan et al. reported that pyruvate kinase M2, which is a rate-limiting enzyme of glycolysis, was downregulated and glucose uptake was inhibited in cells that were exposed to PDT with 5-aminolevulinic acid (5-ALA) at $4 \mathrm{~h}$ after treatment. Interestingly, they reported important increases in PKM2 expression and glucose uptake at $24 \mathrm{~h}$ after PDT (Gan et al., 2020). Such findings suggest that PDT may indeed drive the Warburg effect in a time dependent manner.

5-ALA is a frequently used PDT agent, due to its high endogenous accumulation. It is the first compound in the porphyrin synthesis pathway that results in chlorophyll in plants and heme in mammals (Chilakamarthi and Giribabu, 2017). 5-ALA, which is synthesized under physiological conditions from succinyl coenzyme A and glycine in mitochondria, leads to the biosynthesis of protoporphyrin IX (PpIX), the last precursor of heme in mitochondria. PpIX is then 
catalyzed by ferrochelatase, which produces hemoprotein (heme) by reducing the iron (III) ion to iron (II). At the end of this process, heme is produced. Due to the Warburg effect seen in cancer cells, the enzyme ferrochelatase becomes inactive. This leads to the increased accumulation of PpIX in cancer cells as a result of the utilization of exogenous 5-ALA. As a result of PDT via the photoactive feature of PpIX; ROS and singlet oxygen as well as superoxides increase in the cell, which in turn result in cellular death. In addition to PDT applications with 5-ALA and hexaminolevulinate, which is used as an optical imaging agent in the cystoscopic detection of carcinoma of the bladder, monoclonal antibody conjugated PDT and photoimmunotherapy (PIT) strategies are currently being developed (Inoue, 2017; Railkar and Agarwal, 2018).

\section{Limitations of Photodynamic Therapy}

PDT is generally ineffective for large or deep-seated tumors due to the limited penetration depth of light in biological tissues. One of the major limitations of PDT is that it cannot be applied to the whole body in advanced stage cancer. For this reason, its utilization is limited to the treatment of precancerous lesions and regional malignancies (Brown et al., 2004; Li X. et al., 2020). Difficulty in treating large tumor masses is another issue in terms of clinical PDT. Moreover, singlet oxygen, which is generated as a result of PDT, has a very short half-life. Thus, the effects of PDT are mainly limited to the area of photosensitization (Moan and Berg, 1991). Given the fact that PDT is highly dependent on the presence of oxygen in the tissues, tumor hypoxia can significantly hamper the effectiveness of PDT (Bhandari et al., 2019; Shen et al., 2021). Indeed, depletion of oxygen due to PDT itself might also decrease PDT efficiency. In addition, problems related with skin toxicity should also be taken into account in terms of clinical PDT applications (Borgia et al., 2018).

The period of time between the administration of the drug and the application of light is called the drug-light interval. Optimum drug-light intervals are mostly assumed to be the times at which there is a maximum differential in PS retention between the tumor and normal tissue (Cramers et al., 2003). However, optimum drug-light interval might vary from patient to patient or lesion to lesion (Wang et al., 2021). Such variations render the application of standardized protocols difficult. It should also be borne in mind that tumor destruction via targeting the vascular structures is also an important part of clinical PDT. Thus, plasma levels of the PSs as well as the exposure of endothelial cells to the PSs may prove to be crucial factors for effective PDT. Indeed, $\mathrm{Li}$ and Luo demonstrated that the anti-tumor effects of Photofrin PDT were achieved mostly by the destruction of tumor blood vessels at short drug-light intervals. On the other hand, tumor cells were destroyed directly by PDT mediated cytotoxicity at long drug-light intervals (Li and Luo, 2009). In general, PSs that directly destruct the target cells should have a relatively longer drug-light interval. On the other hand, PSs with a short drug-light interval may be targeted to tumor related vascular structures rather than the tumor cells in order to improve the effectiveness of treatment (Allison and Moghissi, 2013a).
Moreover, the depth of PDT application in cancer treatment is limited, given the fact that light cannot penetrate beyond a few millimeters of tissue (Stolik et al., 2000; Gunaydin et al., 2021). The treatment efficiency decreases in deep-seated and spreading tumors due to the low tissue penetration of light. The deep-PDT strategy, which was developed with new photo converting nanoparticles and/or NIR light/X-ray/self-luminescence excitation methods, aims to overcome this limitation (Fan et al., 2016; Li et al., 2021). One approach takes advantage of the two-photon excitation technique, which involves absorption of two photons in order to reach an excited state (Bolze et al., 2017). This technique, which allows for the activation of PSs with two-photon absorption, may aid in improving light penetration depth (Lan et al., 2017).

\section{Assessment of Photodynamic Therapy Therapeutic Efficacy in the Clinic}

It is of utmost importance to identify early predictors in order to determine the response to treatment. Huang et al. reported that gadolinium contrast-enhanced magnetic resonance imaging (MRI) is superior to diffusion weighted images at 7 days after PDT (Huang et al., 2006). The MRI results correlated with the percentage of necrosis in a canine model (Huang et al., 2006). On the other hand, Haider et al. demonstrated that contrastenhanced MRI showed irregular margins of intra-prostatic treatment effect and suggested that tissue sensitivities to vascular targeted PDT with palladium-bacteriopheophorbide varied (Haider et al., 2007). Sirotkina et al. utilized optical coherence angiography to monitor treatment response following vascular targeted PDT (Sirotkina et al., 2019). In another study, Gross et al. investigated the utilization of blood oxygenation leveldependent contrast MRI in order to monitor real-time efficacy of PDT (Gross et al., 2003). Such an approach might be useful in monitoring PDT treatment. Bioluminescence imaging was also investigated as a means of success rate assessment $24 \mathrm{~h}$ after vascular targeted PDT (Fleshker et al., 2008). Luciferase transfected (luminescent) tumor cells allowed for the imaging of the tumor before and $24 \mathrm{~h}$ after PDT. PDT treatment response was assessed based on the presence of bioluminescence imaging signal. Using the treatment response information, researchers treated the mice that failed the first treatment again; thus, reaching a cumulative treatment success rate of $90 \%$ from $75 \%$ (Fleshker et al., 2008). The utilization of bioluminescence imaging in in vivo animal models may assist in determining response to PDT. Ultrasonography, which is cheaper than MRI, may also prove to be useful in terms of assessing PDT efficacy and it may improve PDT mediated outcomes in cancer. Ultrasonography can be implicated in tracking the uptake of PS, destruction of vessels and evaluating the overall tumor responses (Hester et al., 2020). The tissue distribution of the PS can also be evaluated by taking biopsy samples and analyzing the fluorescence (Moore et al., 2009). Furthermore, strategies to detect intratumoral drug, light and oxygen in order to monitor treatment have also been investigated. In addition to such strategies, computer modelling of PDT can also be helpful, as such approaches may assist PDT in the clinical setting (Jankun et al., 2005). 


\section{Photodynamic Diagnosis}

Several types of PSs can be used for diagnostic purposes in terms of tumors (Beharry, 2018). Such approaches are generally called photodynamic diagnosis (PDD). As its name implies, PDD utilizes fluorescent PS agents in order to identify tumor tissues. In PDD, a PS which is selective for the target tumor cells is utilized (Dobson et al., 2018; Kim and Wilson, 2020; Nompumelelo Simelane et al., 2020; Fukuhara et al., 2021; Luan et al., 2021; Owari et al., 2021). The PS can be excited with a light source at a specific wavelength. The emitted light enables identification of the tumor cells. PDD can be regarded as part of fluorescent guided resection, which is a kind of Image Guided Surgery (Allison, 2016). This approach has the potential to improve clinical outcome. PDD can turn into PDT via increasing the intensity/duration of photoirradiation (Dobson et al., 2018). It should be noted that ROS that are generated in PDT are able to harm the PS, causing the PS to become nonfluorescent. ALA seems to have a potential for PDD in various tumors, due to its ability to discriminate neoplastic tissues from normal tissues (Nokes et al., 2013). ALA fluorescence microscopy has been proposed to be a specific biological tumor marker for malignant glioma resection (Hefti et al., 2010). It may assist in discriminating tumor tissue from normal brain tissue. Stummer et al. reported that ALA enabled more complete resections of contrast-enhancing tumor, resulting in improved progression free survival in patients with malignant glioma (Stummer et al., 2006). Moreover, PDD was reported to detect more bladder tumor-positive patients, especially more with carcinoma in situ, than white-light cystoscopy (Kausch et al., 2010). Kausch et al. concluded that a longer recurrence free survival was achieved and more patients had a complete resection when diagnosed with PDD (Kausch et al., 2010). Similarly, Mowatt et al. reported that PDD identified more bladder tumors than white-light cystoscopy. PDD with ALA enabled a more complete approach at transurethral resection of bladder tumor and improved recurrence-free survival (Mowatt et al., 2011). Turan et al. demonstrated a concept of molecular demultiplexer, which is able to autonomously switch modes from PDT to PDD when apoptosis is induced (Turan et al., 2018). Such an intelligent molecular automaton has shown a way of moving ahead to meet the challenge of confinement of unintended damage by excessive ${ }^{1} \mathrm{O}_{2}$ production. It is clear that early detection of a tumor is very important in terms of improving survival rate. Furthermore, combination of PDD and PDT may prove to be very efficient. Near infrared fluorescence imaging is most likely to improve the concept of tumor targeted imaging, due to the features such as low tissue auto-fluorescence and high tissue penetration depth of near infrared spectrum (Luo et al., 2011).

\section{PHOTODYNAMIC THERAPY COMBINED WITH OTHER THERAPY MODALITIES}

Combination of PDT with other therapeutic modalities seems to be promising in terms of enhancing effectiveness against tumor (Firczuk et al., 2011). Several features of PDT such as minimal systemic effects and low long term morbidity render it a suitable option for combination therapy approaches (Agostinis et al., 2011). PDT has been proposed to be effectively combined with other anti-cancer therapeutic modalities, as the mechanism of action of PDT is unique (Juzeniene et al., 2007). Given the fact that the targets of radiotherapy, chemotherapy and PDT differ; combination of PDT with such treatments may yield better results than by single treatments (Juzeniene et al., 2007). Moreover, the utilization of lower doses in a combination therapy setting may cause less side effects and better results than single therapy (Yoo and Ha, 2012). In a study by Gupta et al., PDT with the use of intratumoral administration of specific antibodies conjugated to PSs was proposed to significantly reduce the toxicity to normal tissues (Gupta et al., 2004). Conjugating PSs with monoclonal antibodies that are specific for antigens on tumor cells may allow for the targeting of tumors (Kwitniewski et al., 2008). Bai et al. proposed that gene therapy and PDT could be combined for treating nasopharyngeal carcinoma (Bai et al., 2011).

\section{PDT Combined With Chemotherapy}

Nahabedian et al. demonstrated that combination of PDT with chemotherapy can yield increased tumoricidal effects (Nahabedian et al., 1988). Several types of tumors were reported to display resistance to platinum analogues and platinum nanomaterials were suggested as possible alternatives for anti-tumor treatment (Chien et al., 2013; Davis et al., 2014; Pedone et al., 2017; Yin et al., 2017; Loveday et al., 2020; Esim et al., 2021). Wang et al. reported that combined chemotherapy and PDT was effective in terms of killing cisplatin resistant tumor cells (Wang et al., 2015). Similarly, Antoni et al. also reported an additive effect of cisplatin and a zinc porphyrin on human ovarian cancer cells (Antoni et al., 2015). Moreover, PDT might be implicated in attenuating drug resistance. Multidrug resistance (MDR) is a critical mechanism, which can cause tumor cells to become resistant to chemotherapeutic drugs (Persidis, 1999). The development of MDR to chemotherapy may constitute an important issue in terms of the treatment of tumors (Gillet and Gottesman, 2010). Several mechanisms have been found to be associated with resistance to chemotherapy such as cellular pumps dependent, increased metabolism of drugs, decreased drug entry and defective apoptotic pathways (Majidinia et al., 2020). Hence, targeting MDR via chemosensitizers combined with anti-tumor compounds is an interesting approach (Avendano and Menendez, 2002). In line with such studies, PDT is able to attenuate multidrug resistance via decreasing drug efflux by lowering P-glycoprotein level (Shi et al., 2017; Zhao et al., 2018). Thus, combination of PDT and chemotherapy may be useful in terms of preventing drug resistance (Li X. et al., 2020). Jin et al. reported that combination of PDT and chemotherapy may prove to be effective against cardiac cancer (Jin et al., 1992). In another study, the combined chemotherapy and PDT with $\mathrm{N}$ (2-hydroxypropyl) methacrylamide copolymer-bound anticancer drugs was shown to be effective against human ovarian carcinoma in nude mice (Peterson et al., 1996). Ma et al. studied the combination of PDT with meso-tetra (di-adjacent- 
sulphonatophenyl) porphine and vincristine or taxol in a mouse mammary tumor model (Ma et al., 1996). They found an increased anti-tumor effect when vincristine was administered $6 \mathrm{~h}$ before PDT. In addition, they also reported that the antitumor activity of PDT could be enhanced when taxol was utilized $6 \mathrm{~h}$ prior to PDT or immediately after or before PDT (Ma et al., 1996). Khdair et al. analyzed the anti-cancer efficacy of doxorubicin in combination with methylene blue mediated PDT in a mouse mammary adenocarcinoma tumor model (Khdair et al., 2010). The results showed that nanoparticle mediated combination chemotherapy and PDT using doxorubicin and methylene blue had a therapeutic potential (Khdair et al., 2010). Canti et al. investigated the effects of PDT with photoactivated aluminum disulfonated phthalocyanine combined with Adriamycin (doxorubicin) and cisplatinum on murine tumors. Mice with leukemia and lymphoma were treated with Adriamycin or cisplatinum and then with PDT. Combination of antiblastic drugs with PDT showed an additive anti-tumor effect. Therefore, such a combination was suggested to have the potential to decrease the effective doses of antiblastic drugs, as well as reducing toxic effects on normal tissues (Canti et al., 1998). Kästle et al. analyzed the effects of combination of PDT with heme oxygenase I and poly (ADP-ribose) polymerase inhibitors on melanoma cells in comparison to nonmalignant keratinocytes (Kastle et al., 2011). The researchers concluded that heme oxygenase I and poly (ADP-ribose) polymerase inhibitors could augment the efficiency of PDT (Kastle et al., 2011).

In addition, combination of PDT with anti-angiogenic drugs may also prove to be useful (Bhuvaneswari et al., 2009). For this purpose, anti-angiogenic monoclonal antibodies may be utilized. Hypoxia is an important feature of several solid tumors and can cause induction of angiogenesis (Gilkes et al., 2014). Zhou et al. reported that efficiency of PDT could be increased by antiangiogenic therapy (Zhou et al., 2005). Ferrario et al. demonstrated that combination of anti-angiogenic treatment and PDT enhanced tumoricidal effects in comparison to individual treatments in mice (Ferrario et al., 2000). In another study, Ferrario et al. showed that bevacizumab (a monoclonal antibody against vascular endothelial growth factor A [VEGF-A]) could augment the efficiency of PDT (Ferrario and Gomer, 2006; Los et al., 2007). They suggested that inhibitors of VEGF have a potential to improve the clinical efficacy of PDT (Ferrario and Gomer, 2006). Similarly, Bhuvaneswari et al. reported that combination of hypericin mediated PDT and bevacizumab improved tumor response (Bhuvaneswari et al., 2007). In addition, another study showed that combination of PDT with anti-angiogenic treatment resulted in inhibition of tumor growth and improved survival in mice in comparison to individual treatments (Jiang et al., 2008). Thus, such a combination approach can be promising in terms of improving clinical results in glioblastoma (Jiang et al., 2008).

\section{PDT Combined With Radiotherapy}

Allman et al. reported that combination of 5-aminolaevulinic acid mediated PDT and gamma-irradiation caused a level of cytotoxicity which is additive and not synergistic (Allman et al.,
2000). Another study by Luksiene et al. showed that hematoporphyrin dimethyl ether mediated PDT and radiotherapy resulted in the inhibition of tumor growth. Furthermore, combining PDT and radiotherapy yielded an additive effect (Luksiene et al., 1999). Nakano et al. reported that the treatment rate of Bowen's disease might be enhanced via combination therapy with 5-aminolevulinic acid mediated PDT and radiation therapy (Nakano et al., 2011). The combinations of two of the modalities of Photofrin II-sensitized photochemotherapy, an electric current and ionizing radiation were reported to act mainly additively or synergistically (Ma et al., 1993).

\section{Photodynamic Therapy Combined With Surgery}

Combinations of PDT with surgery have been studied by several groups. Rigual et al. proposed that adjuvant use of 2-(1hexyloxyethyl)-2-devinyl pyropheophorbide-a (HPPH) mediated PDT and surgery for head and neck squamous cell carcinoma appeared safe (Rigual et al., 2013). Caesar et al. suggested that $m$-tetrahydroxyphenylchlorin (mTHPC) mediated PDT may be utilized as adjuvant therapy to surgery in recurrent tumors of the paranasal sinuses and the anterior skull base where complete resection is not achievable (Caesar et al., 2015). In another study, Doeveren et al. used adjuvant metatetrahydroxyphenylchlorin-mediated PDT in patients with a malignancy in the head and neck with close or positive resection margins who were not eligible for conventional treatment modalities and they reported that PDT could be applied as adjuvant therapy after surgery (van Doeveren et al., 2018). Wang et al. recently proposed that in prostate cancer, PDT might be an effective adjuvant therapy for image-guided surgery (Wang X. et al., 2020). Friedberg et al. reported that Foscan mediated PDT may be safely combined with surgery at the established maximally tolerated dose (Friedberg et al., 2003). Friedberg et al. conducted a phase II trial in order to investigate the effects of combination of surgery with intraoperative PDT on local control and survival in patients with non-small-cell lung cancer with pleural spread. They reported that surgery and PDT might be performed safely with good local control (Friedberg et al., 2004). Sun et al. suggested that PDT with photofrin on young patients with advanced colorectal cancer could be utilized as an adjuvant therapy (Sun et al., 2016). Kuijpers et al. reported four cases of basal cell carcinoma treated with Mohs surgery, where they used PDT with aminolevulinic acid as an adjuvant therapy (Kuijpers et al., 2004). The researchers proposed that the combination of Mohs surgery and PDT might result in the cure of the tumor with good cosmetic results (Kuijpers et al., 2004). Torres et al. conducted a preliminary study which found that methyl-aminolevulinate mediated PDT can be an alternative as an adjunctive therapy before standard surgical excision of morpheaform basal cell carcinoma (Torres et al., 2011). In another study, Nanashima suggested that adjuvant PDT may be a useful option for patients with bile duct carcinoma undergoing surgical resection (Nanashima et al., 2004). Hans-Beat 
Ris suggested that intraoperative PDT following resection can be an attractive treatment for malignant pleural mesothelioma, which may help to reduce local recurrence (Ris, 2005).

\section{Photodynamic Therapy Combined With Immunotherapy}

PDT may also be utilized in combination with immunotherapy. It has the potential to augment anti-tumor immunity (Canti et al., 2010). It is known that generation of effective systemic antitumor immune responses has a great potential to eliminate tumors (Bonavida and Chouaib, 2017; Gonzalez et al., 2018; Labani-Motlagh et al., 2020; Hiam-Galvez et al., 2021). PDT is capable of inducing immunogenic cell death, which is a cell death modality that stimulates immune responses against dead cell antigens (Green et al., 2009; Kroemer et al., 2013; Ng et al., 2018). Furthermore, combining PDT with cancer immunotherapy may demonstrate synergistic results, achieve tumor regression, provide immune memory ( $\mathrm{Ng}$ et al., 2018). In addition to such mechanisms related with immunogenic cell death achieved by PDT, treatment of tumors with infrared laser as a means of autologous vaccination has demonstrated promise in animal studies (Chen et al., 1999; Chen et al., 2001; Chen et al., 2003; Naylor et al., 2006). Thus, the release of tumor antigens can then play roles as in situ auto-vaccines (Naylor et al., 2006; Chen et al., 2016). Furthermore, proinflammatory cytokines, which stimulate the immune responses, are also increased. As a result of such mechanisms, PDT causes an increased dissemination of tumor antigens and damage associated patterns from the target tumors. The antigens are then taken up by dendritic cells, which subsequently present those antigens to $\mathrm{CD}^{+}$and $\mathrm{CD}^{+} \mathrm{T}$ cells. This presentation process results in the activation of adaptive immune responses against the tumor as well as generating immunological memory (Brackett and Gollnick, 2011; Reginato et al., 2014; Maeding et al., 2016; Murata et al., 2016; Alzeibak et al., 2021).

PDT is known to cause inflammation and recruitment of cells such as neutrophils, macrophages (Nowis et al., 2005). Jalili et al. investigated the effectiveness of combining PDT with administration of dendritic cells (Jalili et al., 2004). They reported that administration of immature dendritic cells into the tumors treated with PDT caused effective homing to lymph nodes and stimulated $\mathrm{T}$ and natural killer cells (Jalili et al., 2004). Thus, the researchers suggested that combination of PDT and administration of immature dendritic cells might demonstrate a potential for clinical use (Jalili et al., 2004). In another study, Saji et al. analyzed whether PDT followed by intratumoral administration of naive dendritic cells might stimulate anti-tumor immunity. They reported that PDT and intratumoral injection of dendritic cells resulted in systemic anti-tumor immunity in mice (Saji et al., 2006). PDT and low dose cyclophosphamide were shown to generate anti-tumor immunity in a study, which suggested that low dose cyclophosphamide depleted regulatory $\mathrm{T}$ cells and potentiated PDT (Castano et al., 2008). It was demonstrated that the combination of vinorelbine, PDT with metatetrahydroxyphenylchlorin and immune lymphocytes had a significant synergistic anti-tumor effect (Canti et al., 2010). In addition, similar results were obtained with the combination of cisplatin, PDT and immune lymphocytes (Canti et al., 2010).

Another interesting approach to combine PDT and immunotherapy relies on the generation of cancer vaccines by PDT, since such an approach has a potential to present tumor antigens (Korbelik, 2010). The PDT vaccine can be generated ex vivo/in situ. The vaccine can then be administered in order to eliminate tumor cells (Korbelik, 2019). Korbelik and Sun generated a whole tumor cell vaccine by in vitro PDT with benzoporphyrin derivative. They proposed that PDT may be utilized in order to generate efficient tumor vaccines (Korbelik and Sun, 2006). Gollnick et al. investigated PDT-generated murine tumor cell lysates and found that PDT-generated tumor cell lysates could be effective vaccines. In addition, they also reported that such vaccines were more efficient than those generated by UV or ionizing irradiation (Gollnick et al., 2002). Garg et al. combined dendritic cell immunotherapy and immunogenic cell death induced by PDT with hypericin. They suggested that immunogenic cell death based vaccines have the potential for translation to the clinical setting (Garg et al., 2016). In another study, Zhang et al. reported that 5-aminolevulinic acid mediated PDT dendritic cell vaccine might stimulate immune responses against tumors (Zhang H. et al., 2018). Similarly, Trempolec et al. reported that a PDT dendritic cell vaccine resulted in a considerable increase in IFN $\gamma^{+} \mathrm{T}$ cells and suggested that PDT dendritic cell vaccines may stimulate antitumor immune responses (Trempolec et al., 2020). Korbelik et al. suggested that surgically removed tumor tissues may be utilized for PDT-based vaccines. Such an approach would allow for the customization of therapeutic interventions (Korbelik et al., 2007). Thus, PDT-based vaccines hold the potential for precision medicine applications. Doix et al. investigated the effects of the dose of PS and PDT scheduling on immunity. Their findings suggested that the timing for the administration of PDT dendritic cell vaccine was important, since the administration of the vaccine before radiotherapy failed to increase tumor growth inhibition, whereas administration of the vaccine around/near radiotherapy resulted in considerable delay in tumor growth (Doix et al., 2019). A recent study reported that the semisynthetic biopolymer $\mathrm{N}$-dihydrogalactochitosan increased the effectiveness of PDT tumor vaccines (Korbelik et al., 2019). Future studies about tumor vaccine related mechanisms are required, in order to be able to translate such approaches to the clinical use.

The effects of PDT on immune responses may in fact synergize with the effects of immunotherapeutic applications, such as the approaches aimed at attenuating the immune suppression in the tumor milieu via utilizing immune checkpoint inhibitors (e.g., anti-PD-L1, anti-PD-1 and anti-CTLA-4) (Kleinovink et al., 2017; Cramer et al., 2020; Xu et al., 2020). Mechanisms of immune checkpoint inhibition can be seen in Figure 7 . Immune checkpoint inhibition has the potential to induce tumor infiltrating lymphocytes (Darvin et al., 2018; Robert, 2020; Park et al., 2021). Given the fact that anti-tumor immune responses may be suppressed due to the effects of 


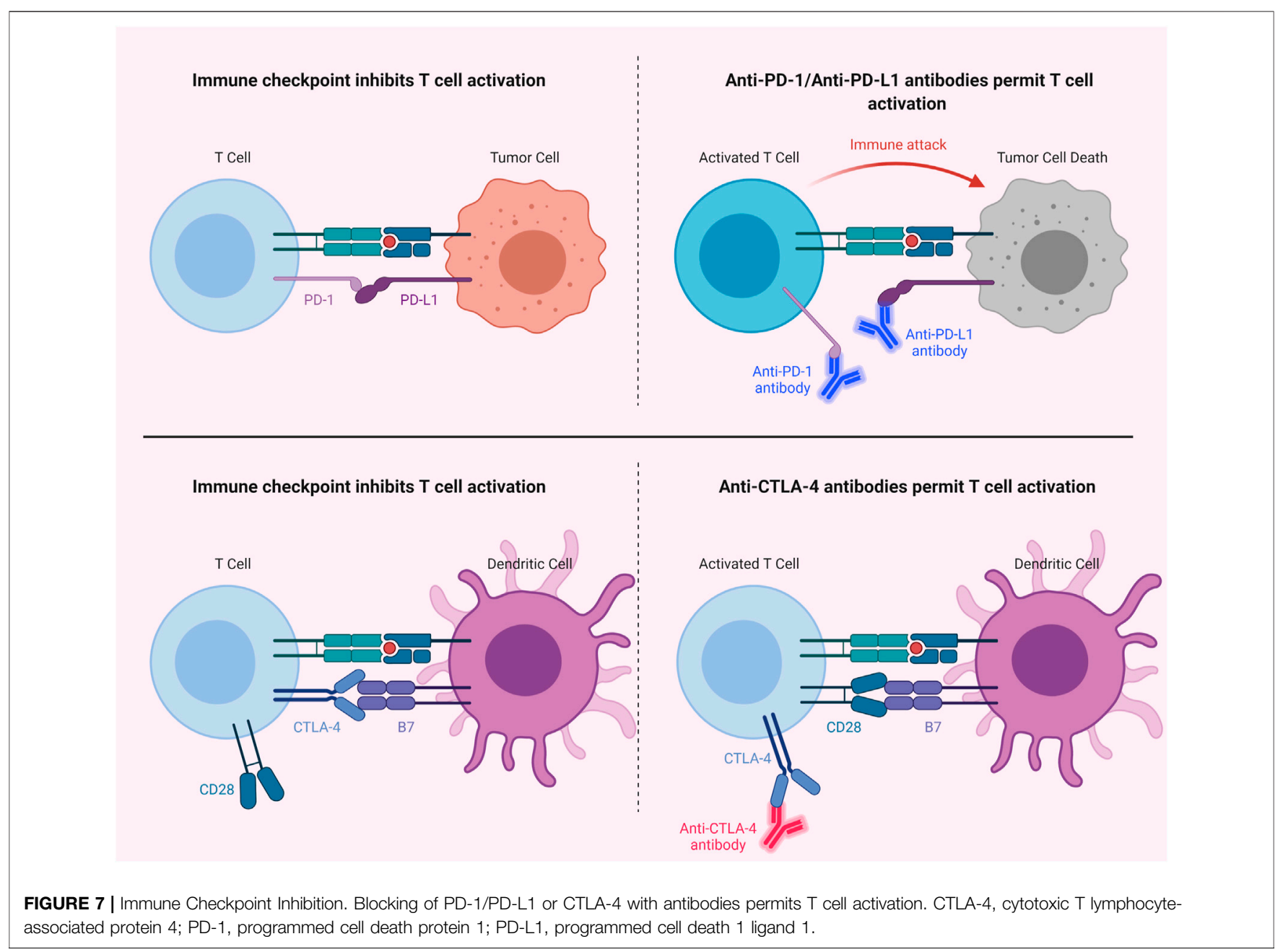

tumor cells on T cells via the programmed cell death 1 ligand 1 (PD-L1)/programmed cell death protein 1 (PD-1) immune checkpoint axis, PDT mediated cancer immunotherapy may be enhanced through targeting PD-L1 in tumor cells (Han et al., 2020; Lotfinejad et al., 2020). Wang et al. reported that combining PDT with PD-L1 knockdown demonstrated higher efficiency in terms of suppressing tumor growth and distant metastasis compared to only-PDT in a murine melanoma xenograft model (Wang et al., 2016). In another study, Dai et al. showed that PDT combined with PD-L1-blockade siRNA approach can stimulate a PDT-induced immune response and may be effective against immune resistance mediated by PD-L1 (Dai et al., 2018). He et al. demonstrated that PDT with nanoscale coordination polymer core-shell nanoparticles that carry oxaliplatin in the core and the PS pyropheophorbide-lipid conjugate in the shell combined with anti-PD-L1 suppressed the growth of both primary and distant tumors in murine colorectal cancer models (He et al., 2016). Duan et al. showed that PDT with Zn-pyrophosphate nanoparticles loaded with the PS pyrolipid sensitized tumors to checkpoint inhibition by a PDL1 antibody. The approach could eliminate primary breast tumors and prevent lung metastasis (Duan et al., 2016). In another study, PDT with Fe-TBP was reported to enhance the efficiency of anti-PD-L1 treatment in a mouse colorectal cancer model (Lan et al., 2018). In addition, it induced abscopal effects. Moreover, PDT with Fe-TBP induced tumor cytotoxic T cell infiltration (Lan et al., 2018). Moreover, Santos et al. reported a favorable outcome in a clinical case with head and neck cancer, utilizing PDT with Redaporfin followed by an anti-PD-1 antibody (Santos et al., 2018).

In addition to the PD-1/PD-L1 axis, blockade of cytotoxic T lymphocyte-associated protein 4 (CTLA-4) checkpoint has also been studied in combination with PDT (Meng et al., 2019; Liu et al., 2021). Xu et al. reported that an immune-stimulating upconversion nanoparticle-based PDT approach in combination with CTLA-4 checkpoint blockade could effectively target primary tumors and suppress distant tumors, as well as inducing immunological memory (Xu et al., 2017). Furthermore, combination of PDT with indoleamine-2,3dioxygenase (IDO) targeting may also prove to be a useful approach to stimulate immunity (Song et al., 2018); since, IDO is an enzyme which shows an immunosuppressive effect via tryptophan depletion, thereby helping tumors to escape from immunity (Moon et al., 2015). In addition, Lu et al. observed 
higher $\mathrm{T}$ cell infiltration in the tumor microenvironment with the combination of IDO inhibition and PDT induced immunogenic cell death (Lu et al., 2016). In light of the current literature, the combination of PDT and immunotherapy may not only efficiently eliminate the target tumor; but also can take out tumor cells and metastases. Such an approach can also provide immunological memory to preclude recurrence.

Even though a myriad of studies reported favorable outcomes in in vitro and in vivo investigations, further studies are required for the effective combination of PDT with other therapeutic modalities in the clinic.

\section{PHOTODYNAMIC THERAPY IN DIFFERENT TYPES OF CANCERS}

As a noninvasive treatment, PDT is mostly utilized for the treatment of nonmelanoma skin cancer as well as precancerous lesions. In addition, PDT may also be utilized in order to treat internal tumors in several parts of the body. Such applications are achieved via administering a systemic PS and then applying specific light via an optical fiber (MacCormack, 2006). Indeed, various clinical applications in the fields of dermatology, gastroenterology, neurosurgery, pneumology, gynecology, urology and ophthalmology may demonstrate promising outcomes for the treatment of tumors (Verger et al., 2021).

\section{Photodynamic Therapy in Colorectal Cancer}

Colorectal cancer is the third most common type of cancer with high invasive character and metastatic potential. Therefore, it constitutes an important clinical issue in which alternative treatments are investigated in addition to conventional therapies. There exist several PDT trials based on ALA and photofrin in colorectal cancer. In addition to these PDT approaches, novel treatment strategies are also being investigated (Kawczyk-Krupka et al., 2015).

The opinion that cancer stem cells are formed due to various genetic or epigenetic changes in adult normal stem cells in the human body has become an important perspective in recent years (Chaffer and Weinberg, 2011; Kreso and Dick, 2014; Ajani et al., 2015). In order to achieve this transformation, various genetic mutations and epigenetic modifications should be acquired. Although the cancer stem cell populations differ according to cancer type, they are very scarce (on average 0-2\%) in the cancer tissue compared to other cell populations. Increased cancer stem cell proliferation in cancerous tissue shows a positive correlation with cancer's aggressive character (Dalerba et al., 2007; Quintana et al., 2008; Eppert et al., 2011; Islam et al., 2015). It is stated that targeting cancer stem cells with PDT-mediated active or passive targeting strategies in colorectal cancer may be an important treatment approach, especially in metastatic colon cancer (Hodgkinson et al., 2017). In a study conducted on a colon cancer mouse model, it is stated that the cells undergo apoptosis as a result of PDT with chlorin-based nanoscale metal-organic framework ( $\mathrm{Lu}$ et al., 2015). In addition, the combined use of PDT with chemo- radiotherapy may improve overall survival in advanced stage of cholangiocarcinoma (Triesscheijn et al., 2006; Yanovsky et al., 2019).

\section{Photodynamic Therapy in Lung Cancer}

Studies on PDT in lung cancer have been carried out for several years. PDT alone was reported to be an important alternative treatment to palliative chemotherapy or radiotherapy in lung cancer. It results in a response rate of approximately $87 \%$ as well as improving the patient's quality of life (Wang et al., 2021). In a study conducted on A549 lung cancer cells, PDT mediated with a nanobody complex (Nb@IC-NPs) was able to effectively destruct tumor cells and improve survival in mice (Zhang et al., 2020). PDT can be used in combination with chemotherapy, radiotherapy and surgery to treat non-small-cell lung cancer. It is proposed that PSs such as temoporfin, 2-[1-hexyloxyethyl]2-devinyl pyropheophorbide-a, and chlorin e6 demonstrate more favorable toxicity profiles (Triesscheijn et al., 2006; Yanovsky et al., 2019). It was suggested that Photofrin-PDT might be useful as a palliative treatment in lung cancer. However, the efficacy of this method decreases in advanced cancers. It is proposed that current PSs such as talaporfin and HPPH, which have high absorption at longer wavelengths, are more effective than the first-generation photofrin (Allison et al., 2011; van Straten et al., 2017; Yang et al., 2021).

\section{Photodynamic Therapy in Prostate Cancer}

Prostate cancer is the most frequent cancer in males and it is the second leading cause of cancer death in men in United States (Siegel et al., 2020). Conventional therapies may cause prominent side effects. For this reason, focal therapies such as cryotherapy or PDT are important (Gheewala et al., 2017). Although padoporfin and motexafin lutetium (MLu) based PDTs may show effective results, it has been noted that PDT approaches used in prostate cancer treatment have various toxic effects. Therefore, it is necessary to revise the treatment strategy by performing dosimetric analyses (Agostinis et al., 2011; Moore et al., 2011).

\section{Photodynamic Therapy in Head \& Neck Cancer}

Head and neck cancer is responsible from more than 650,000 cases and 330,000 deaths annually worldwide (Bray et al., 2018; Stenson, 2021). Temoporfin-based PDT can be used as a treatment method in advanced-stage head and neck cancers when surgery and radiotherapy may be insufficient (Li X. et al., 2020). Photofrin PDT, which is used in patients diagnosed with nasopharyngeal carcinoma and relapsed due to conventional treatments such as fluorouracil and cisplatin, has been reported to be more effective than conventional treatment (Li et al., 2006; Agostinis et al., 2011).

\section{Photodynamic Therapy in Brain Cancer}

Malignant gliomas may be fatal tumors. Additionally, posttreatment recurrence rates are approximately 80\%. Current treatment strategies result in an overall survival of about 15 months (Quirk et al., 2015). PSs can be used for both PDD and PDT purposes in brain tumors. It was reported that ALAbased malignant glioma surgery could increase overall survival 
compared to the control group (Stummer et al., 2006; Agostinis et al., 2011).

\section{Photodynamic Therapy in Skin Cancer}

PDT is frequently used in skin diseases, especially in nonmelanoma skin cancer and precancerous cutaneous lesions. Over 10 million patients have been reported to be treated with PDT so far (Li X. et al., 2020). PDT is generally preferred in the treatment of actinic keratosis (AK). It was stated that ALA-based PDT is a more effective treatment strategy compared to the cryotherapy used in AK treatment. It was reported that MAL-PDT (methyl aminolevulinate) applied in the treatment of squamous cell carcinoma in situ might achieve $88-100 \%$ elimination of the lesions. Although the efficiency of PDT treatment in basal cell carcinoma is similar to cryotherapy and surgical application, PDT provides easy application for difficult areas such as eye lesions (Triesscheijn et al., 2006; Yanovsky et al., 2019).

\section{Photodynamic Therapy in Pancreas Cancer}

Pancreas cancer is another type of cancer with high fatality. The 5years survival in pancreas cancer is less than $10 \%$. Current therapeutic strategies may cause adverse effects (Wang Y. et al., 2020). For this reason, various clinical and preclinical trials are ongoing in the setting of pancreas cancer. Phase studies with benzoporphyrin-based PDT in pancreas cancer may yield results associated with low morbidity (van Straten et al., 2017; Yang et al., 2021). Bown et al. utilized PDT with meso-tetrahydroxyphenyl chlorin in pancreas cancer (Bown et al., 2002). They reported that PDT could produce necrosis in pancreatic cancers with an acceptable morbidity. In another study, Huggett et al. suggested that Verteporfin PDT-induced tumor necrosis is feasible and safe in locally advanced pancreatic cancer (Huggett et al., 2014).

\section{Photodynamic Therapy in Breast Cancer}

Breast cancer is the most common cancer among women. It demonstrates a complex genetic basis in terms of susceptibility. As a result of the treatment strategies applied for breast cancer, adverse effects and resistance to treatment may occur in some breast cancer subtypes. The new treatment strategies include biomimetic hydrogels encapsulating ROS - sensitive tegafur (TF) and protoporphyrin IX (PpIX) heterodimers (TTP), which aim to utilize chemotherapy and PDT synergistically in order to minimize the side effects that occur during conventional treatment (Aniogo et al., 2019; Zhang et al., 2021).

\section{Photodynamic Therapy in Cervix Cancer}

Cervical cancer is the fourth most common cancer in women (Bray et al., 2018; Arbyn et al., 2020). It is estimated that cervical cancer accounted for 604,000 new cancer cases and 342,000 deaths worldwide in 2020 (Sung et al., 2021). Although conventional treatments have effective responses, cervical stroma is damaged in most patients due to these treatments. In this context, PDT emerges as an effective and harmless treatment strategy (Li D. et al., 2020). Phase studies with ALA-based PDT in cervical cancer have yielded results associated with low morbidity (Allison et al., 2011; van Straten et al., 2017; Yang et al., 2021). A study conducted with HeLa cells showed that cellular uptake increased with phthalocyanine conjugated gold nanoparticles. In addition, the caspase $3 / 7$ pathway was suggested to be activated in the cells as a result of PDT (Wieder et al., 2006).

\section{CONCLUDING REMARKS}

Various novel PDT approaches have been studied and developed over the last decades in order to be used against tumors. Preclinical and clinical applications of PDT and PDD have yielded promising results. Topical and systemic administrations of PSs have been utilized in the clinical setting. In addition, several PDT approaches have been approved by major regulatory bodies including the FDA in the United States and the European Medicines Agency (EMA) in Europe. Although we have witnessed a considerable progress in understanding the mechanisms associated with PDT and PDD, the systemic applications of PSs still require further developments. Furthermore, the biophysical features of the constituents of PDT (i.e., PS, light, oxygen) may still represent limitations for the clinical applications of PDT, especially for deep tissue seated hypoxic tumors. Targeted approaches especially in the setting of precision medicine may pave the way for more efficient and widespread utilization of PDT in the clinic. Numerous studies have concentrated on improving the effectiveness and specificity of PDT for specific tumor cells. Such studies demonstrated that various approaches including nanoparticles could be used to achieve such goals. In addition, tumor related cues may also be used as biomarkers. Thus, approaches that target such cues have the potential to improve the specificity of the treatment, as well as decreasing systemic adverse effects. Furthermore, the combination of PDT with other therapeutic modalities such as chemotherapy, immunotherapy, etc. has demonstrated favorable results. Various studies are ongoing in terms of the efforts to determine the optimal combination approaches. Moreover, preclinical interest in designing state-of-the-art PSs for use in PDT or PDD will facilitate the development of more capable and advanced agents. It should also be noted that there are several clinical trials in progress, currently. The importance of the ease of applicability and effectiveness of new treatment modalities in comparison to standard approaches should also be kept in mind. Reasonable strategies may be helpful for clinical translation of novel PDT modalities; thus, allowing for more common use of PDT. In addition to the development of more refined PSs, a better understanding of the effectiveness of PDT in a combination setting in the clinic as well as the optimization of such complex multimodal treatments will expand the clinical applications of PDT.

\section{AUTHOR CONTRIBUTIONS}

GG, MG and SA prepared the manuscript. Figures 2-7 were created with BioRender.com.

\section{ACKNOWLEDGMENTS}

"There is remedy for all things except death." Dedicated to the memory of my beloved Dad Nejat Sahin GUNAYDIN, MD (1953-2021). 


\section{REFERENCES}

Abdel-kader, M. H. (2016). "CHAPTER 1. The Journey of PDT throughout History: PDT from Pharos to Present," in Photodynamic Medicine. Editors H. Kostron and T. Hasan (Cambridge, UK: The Royal Society of Chemistry), 1-21. doi:10.1039/9781782626824-00001

Abrahamse, H., and Hamblin, M. R. (2016). New Photosensitizers for Photodynamic Therapy. Biochem. J. 473 (4), 347-364. doi:10.1042/ BJ20150942

Abrahamse, H., Kruger, C. A., Kadanyo, S., and Mishra, A. (2017). Nanoparticles for Advanced Photodynamic Therapy of Cancer. Photomed. Laser Surg. 35 (11), 581-588. doi:10.1089/pho.2017.4308

Ackroyd, R., Kelty, C., Brown, N., and Reed, M. (2001). The History of Photodetection and Photodynamic Therapy. Photochem. Photobiol. 74 (5), 656-669. doi:10.1562/0031-8655(2001)074<0656:thopap >2.0.co;2

Agostinis, P., Berg, K., Cengel, K. A., Foster, T. H., Girotti, A. W., Gollnick, S. O., et al. (2011). Photodynamic Therapy of Cancer: an Update. CA: A Cancer J. Clinicians 61 (4), 250-281. doi:10.3322/caac.20114

Ajani, J. A., Song, S., Hochster, H. S., and Steinberg, I. B. (2015). Cancer Stem Cells: the Promise and the Potential. Semin. Oncol. 42 (Suppl. 1), S3-S17. doi:10.1053/ j.seminoncol.2015.01.001

Allison, R. R., and Moghissi, K. (2013a). Oncologic Photodynamic Therapy: Clinical Strategies that Modulate Mechanisms of Action. Photodiagn. Photodyn. Ther. 10 (4), 331-341. doi:10.1016/j.pdpdt.2013.03.011

Allison, R. R., and Moghissi, K. (2013b). Photodynamic Therapy (PDT): PDT Mechanisms. Clin. Endosc. 46 (1), 24-29. doi:10.5946/ce.2013.46.1.24

Allison, R. R., Downie, G. H., Cuenca, R., Hu, X.-H., Childs, C. J., and Sibata, C. H. (2004). Photosensitizers in Clinical PDT. Photodiagn. Photodyn. Ther. 1 (1), 27-42. doi:10.1016/S1572-1000(04)00007-9

Allison, R., Moghissi, K., Downie, G., and Dixon, K. (2011). Photodynamic Therapy (PDT) for Lung Cancer. Photodiagn. Photodyn. Ther. 8 (3), 231-239. doi:10.1016/j.pdpdt.2011.03.342

Allison, R. R. (2014). Photodynamic Therapy: Oncologic Horizons. Future Oncol. 10 (1), 123-124. doi:10.2217/fon.13.176

Allison, R. R. (2016). Fluorescence Guided Resection (FGR): A Primer for Oncology. Photodiagn. Photodyn. Ther. 13, 73-80. doi:10.1016/ j.pdpdt.2015.11.008

Allman, R., Cowburn, P., and Mason, M. (2000). Effect of Photodynamic Therapy in Combination with Ionizing Radiation on Human Squamous Cell Carcinoma Cell Lines of the Head and Neck. Br. J. Cancer 83 (5), 655-661. doi:10.1054/ bjoc. 2000.1328

Alzeibak, R., Mishchenko, T. A., Shilyagina, N. Y., Balalaeva, I. V., Vedunova, M. V., and Krysko, D. V. (2021). Targeting Immunogenic Cancer Cell Death by Photodynamic Therapy: Past, Present and Future. J. Immunother. Cancer 9 (1), e001926. doi:10.1136/jitc-2020-001926

Aniogo, E. C., Plackal Adimuriyil George, B., and Abrahamse, H. (2019). The Role of Photodynamic Therapy on Multidrug Resistant Breast Cancer. Cancer Cel Int 19, 91. doi:10.1186/s12935-019-0815-0

Antoni, P. M., Naik, A., Albert, I., Rubbiani, R., Gupta, S., Ruiz-Sanchez, P., et al. (2015). (Metallo)porphyrins as Potent Phototoxic Anti-cancer Agents after Irradiation with Red Light. Chem. Eur. J. 21 (3), 1179-1183. doi:10.1002/ chem. 201405470

Arbyn, M., Weiderpass, E., Bruni, L., de Sanjosé, S., Saraiya, M., Ferlay, J., et al. (2020). Estimates of Incidence and Mortality of Cervical Cancer in 2018: a Worldwide Analysis. Lancet Glob. Health 8 (2), e191-e203. doi:10.1016/S2214109X(19)30482-6

Avendaño, C., and Menéndez, J. C. (2015). "Anticancer Drugs Acting via Radical Species," in Medicinal Chemistry of Anticancer Drugs. Editors C. Avendaño and J. C. Menéndez (Boston: Elsevier), 133-195. doi:10.1016/b978-0-444-626493.00004-1

Avendano, C., and Menendez, J. (2002). Inhibitors of Multidrug Resistance to Antitumor Agents (MDR). Cmc 9 (2), 159-193. doi:10.2174/ 0929867023371175

Ayan, S., Gunaydin, G., Yesilgul-Mehmetcik, N., Gedik, M. E., Seven, O., and Akkaya, E. U. (2020). Proof-of-principle for Two-Stage Photodynamic Therapy: Hypoxia Triggered Release of Singlet Oxygen. Chem. Commun. 56 (94), 14793-14796. doi:10.1039/d0cc06031c
Bai, D., Xia, X., Yow, C. M. N., Chu, E. S. M., and Xu, C. (2011). Hypocrellin B-Encapsulated Nanoparticle-Mediated Rev-Caspase-3 Gene Transfection and Photodynamic Therapy on Tumor Cells. Eur. J. Pharmacol. 650 (2-3), 496-500. doi:10.1016/j.ejphar.2010.10.017

Barras, A., Skandrani, N., Gonzalez Pisfil, M., Paryzhak, S., Dumych, T., Haustrate, A., et al. (2018). Improved Photodynamic Effect through Encapsulation of Two Photosensitizers in Lipid Nanocapsules. J. Mater. Chem. B 6 (37), 5949-5963. doi:10.1039/c8tb01759j

Baskaran, R., Lee, J., and Yang, S.-G. (2018). Clinical Development of Photodynamic Agents and Therapeutic Applications. Biomater. Res. 22, 25. doi:10.1186/s40824-018-0140-z

Bazylińska, U., Pietkiewicz, J., Saczko, J., Nattich-Rak, M., Rossowska, J., Garbiec, A., et al. (2012). Nanoemulsion-templated Multilayer Nanocapsules for Cyanine-type Photosensitizer Delivery to Human Breast Carcinoma Cells. Eur. J. Pharm. Sci. 47 (2), 406-420. doi:10.1016/j.ejps.2012.06.019

Beharry, A. A. (2018). Next-Generation Photodynamic Therapy: New Probes for Cancer Imaging and Treatment. Biochemistry 57 (2), 173-174. doi:10.1021/ acs.biochem.7b01037

Bhandari, V., Hoey, C., Liu, L. Y., Lalonde, E., Ray, J., Livingstone, J., et al. (2019). Molecular Landmarks of Tumor Hypoxia across Cancer Types. Nat. Genet. 51 (2), 308-318. doi:10.1038/s41588-018-0318-2

Bhuvaneswari, R., Yuen, G. Y., Chee, S. K., and Olivo, M. (2007). Hypericinmediated Photodynamic Therapy in Combination with Avastin (Bevacizumab) Improves Tumor Response by Downregulating Angiogenic Proteins. Photochem. Photobiol. Sci. 6 (12), 1275-1283. doi:10.1039/b705763f

Bhuvaneswari, R., Gan, Y. Y., Soo, K. C., and Olivo, M. (2009). The Effect of Photodynamic Therapy on Tumor Angiogenesis. Cell. Mol. Life Sci. 66 (14), 2275-2283. doi:10.1007/s00018-009-0016-4

Bolze, F., Jenni, S., Sour, A., and Heitz, V. (2017). Molecular Photosensitisers for Two-Photon Photodynamic Therapy. Chem. Commun. 53 (96), 12857-12877. doi:10.1039/c7cc06133a

Bonavida, B., and Chouaib, S. (2017). Resistance to Anticancer Immunity in Cancer Patients: Potential Strategies to Reverse Resistance. Ann. Oncol. 28 (3), 457-467. doi:10.1093/annonc/mdw615

Borgia, F., Giuffrida, R., Caradonna, E., Vaccaro, M., Guarneri, F., and Cannavo, S. P. (2018). Early and Late Onset Side Effects of Photodynamic Therapy. Biomedicines 6 (1), 12. doi:10.3390/biomedicines6010012

Bown, S. G., Rogowska, A. Z., Whitelaw, D. E., Lees, W. R., Lovat, L. B., Ripley, P., et al. (2002). Photodynamic Therapy for Cancer of the Pancreas. Gut 50 (4), 549-557. doi:10.1136/gut.50.4.549

Brackett, C. M., and Gollnick, S. O. (2011). Photodynamic Therapy Enhancement of Anti-tumor Immunity. Photochem. Photobiol. Sci. 10 (5), 649-652. doi:10.1039/c0pp00354a

Brancaleon, L., and Moseley, H. (2002). Laser and Non-laser Light Sources for Photodynamic Therapy. Lasers Med. Sci. 17 (3), 173-186. doi:10.1007/ s101030200027

Bray, F., Ferlay, J., Soerjomataram, I., Siegel, R. L., Torre, L. A., and Jemal, A. (2018). Global Cancer Statistics 2018: GLOBOCAN Estimates of Incidence and Mortality Worldwide for 36 Cancers in 185 Countries. CA: A Cancer J. Clinicians 68 (6), 394-424. doi:10.3322/caac.21492

Brown, S. B., Brown, E. A., and Walker, I. (2004). The Present and Future Role of Photodynamic Therapy in Cancer Treatment. Lancet Oncol. 5 (8), 497-508. doi:10.1016/S1470-2045(04)01529-3

Bryan, C. P. t. (1930). The Papyrus Ebers/Translated from the German Version by Cyril P. Bryan ... With an Introduction by Professor J. Elliot Smith. London: G. Bles.

Bugaj, A. M. (2011). Targeted Photodynamic Therapy - a Promising Strategy of Tumor Treatment. Photochem. Photobiol. Sci. 10 (7), 1097-1109. doi:10.1039/ c0pp00147c

Burstein, H. J. (2005). The Distinctive Nature of HER2-Positive Breast Cancers. N. Engl. J. Med. 353 (16), 1652-1654. doi:10.1056/NEJMp058197

Caesar, L., van Doeveren, T. E. M., Tan, I. B., Dilci, A., van Veen, R. L. P., and Karakullukcu, B. (2015). The Use of Photodynamic Therapy as Adjuvant Therapy to Surgery in Recurrent Malignant Tumors of the Paranasal Sinuses. Photodiagn. Photodyn. Ther. 12 (3), 414-421. doi:10.1016/ j.pdpdt.2015.06.001

Canti, G., Nicolin, A., Cubeddu, R., Taroni, P., Bandieramonte, G., and Valentini, G. (1998). Antitumor Efficacy of the Combination of Photodynamic Therapy 
and Chemotherapy in Murine Tumors. Cancer Lett. 125 (1-2), 39-44. doi:10.1016/s0304-3835(97)00502-8

Canti, G., Calastretti, A., Bevilacqua, A., Reddi, E., Palumbo, G., and Nicolin, A. (2010). Combination of Photodynamic Therapy + Immunotherapy + Chemotherapy in Murine Leukiemia. neo 57 (2), 184-188. doi:10.4149/ neo_2010_02_184

Carmeliet, P., and Jain, R. K. (2011). Principles and Mechanisms of Vessel Normalization for Cancer and Other Angiogenic Diseases. Nat. Rev. Drug Discov. 10 (6), 417-427. doi:10.1038/nrd3455

Castano, A. P., Demidova, T. N., and Hamblin, M. R. (2005). Mechanisms in Photodynamic Therapy: Part Three-Photosensitizer Pharmacokinetics, Biodistribution, Tumor Localization and Modes of Tumor Destruction. Photodiagnosis Photodynamic Ther. 2 (2), 91-106. doi:10.1016/S15721000(05)00060-8

Castano, A. P., Mroz, P., and Hamblin, M. R. (2006). Photodynamic Therapy and Anti-tumour Immunity. Nat. Rev. Cancer 6 (7), 535-545. doi:10.1038/ nrc1894

Castano, A. P., Mroz, P., Wu, M. X., and Hamblin, M. R. (2008). Photodynamic Therapy Plus Low-Dose Cyclophosphamide Generates Antitumor Immunity in a Mouse Model. Proc. Natl. Acad. Sci. 105 (14), 5495-5500. doi:10.1073/ pnas.0709256105

Ceglia, L., and Toni, R. (2018). "Vitamin D and Muscle Performance in Athletes," in Vitamin D and Muscle Performance in Athletes. Editor D. Feldman (Academic Press), 1121-1130. doi:10.1016/b978-0-12-809963-6.00113-9

Chaffer, C. L., and Weinberg, R. A. (2011). A Perspective on Cancer Cell Metastasis. Science 331 (6024), 1559-1564. doi:10.1126/science.1203543

Chen, W. R., Zhu, W.-G., Dynlacht, J. R., Liu, H., and Nordquist, R. E. (1999). Long-term Tumor Resistance Induced by Laser Photo-Immunotherapy. Int. J. Cancer 81 (5), 808-812. doi:10.1002/(sici)1097-0215(19990531)81:5<808:: aid-ijc23>3.0.co; $2-\mathrm{j}$

Chen, W. R., Singhal, A. K., Liu, H., and Nordquist, R. E. (2001). Antitumor Immunity Induced by Laser Immunotherapy and its Adoptive Transfer. Cancer Res. 61 (2), 459-461.

Chen, W. R., Jeong, S. W., Lucroy, M. D., Wolf, R. F., Howard, E. W., Liu, H., et al. (2003). Induced Antitumor Immunity against DMBA-4 Metastatic Mammary Tumors in Rats Using Laser Immunotherapy. Int. J. Cancer 107 (6), 1053-1057. doi:10.1002/ijc.11501

Chen, Q., Wen, J., Li, H., Xu, Y., Liu, F., and Sun, S. (2016). Recent Advances in Different Modal Imaging-Guided Photothermal Therapy. Biomaterials 106, 144-166. doi:10.1016/j.biomaterials.2016.08.022

Chien, C.-T., Yan, J.-Y., Chiu, W.-C., Wu, T.-H., Liu, C.-Y., and Lin, S.-Y. (2013). Caged Pt Nanoclusters Exhibiting Corrodibility to Exert Tumor-Inside Activation for Anticancer Chemotherapeutics. Adv. Mater. 25 (36), 5067-5073. doi:10.1002/adma.201302363

Chilakamarthi, U., and Giribabu, L. (2017). Photodynamic Therapy: Past, Present and Future. Chem. Rec. 17 (8), 775-802. doi:10.1002/tcr.201600121

Clarke, C. P., Knight, S. R., Daniel, F. J., and Seevanayagam, S. (2006). Management of Malignant Mesothelioma by Decortication and Adjunct Phototherapy. Asian Cardiovasc. Thorac. Ann. 14 (3), 206-209. doi:10.1177/021849230601400307

Cramer, G. M., Moon, E. K., Cengel, K. A., and Busch, T. M. (2020). Photodynamic Therapy and Immune Checkpoint Blockade †. Photochem. Photobiol. 96 (5), 954-961. doi:10.1111/php.13300

Cramers, P., Ruevekamp, M., Oppelaar, H., Dalesio, O., Baas, P., and Stewart, F. A. (2003). Foscan Uptake and Tissue Distribution in Relation to Photodynamic Efficacy. Br. J. Cancer 88 (2), 283-290. doi:10.1038/sj.bjc.6600682

Dąbrowski, J. M., and Arnaut, L. G. (2015). Photodynamic Therapy (PDT) of Cancer: from Local to Systemic Treatment. Photochem. Photobiol. Sci. 14 (10), 1765-1780. doi:10.1039/c5pp00132c

Dai, L., Li, K., Li, M., Zhao, X., Luo, Z., Lu, L., et al. (2018). Size/Charge Changeable Acidity-Responsive Micelleplex for Photodynamic-Improved PD-L1 Immunotherapy with Enhanced Tumor Penetration. Adv. Funct. Mater. 28 (18), 1707249. doi:10.1002/adfm.201707249

Dalerba, P., Cho, R. W., and Clarke, M. F. (2007). Cancer Stem Cells: Models and Concepts. Annu. Rev. Med. 58, 267-284. doi:10.1146/ annurev.med.58.062105.204854

Daniell, M. D., and Hill, J. S. (1991). A History of Photodynamic Therapy. ANZ J. Surg. 61 (5), 340-348. doi:10.1111/j.1445-2197.1991.tb00230.x
Darvin, P., Toor, S. M., Sasidharan Nair, V., and Elkord, E. (2018). Immune Checkpoint Inhibitors: Recent Progress and Potential Biomarkers. Exp. Mol. Med. 50 (12), 1-11. doi:10.1038/s12276-018-0191-1

Dave, D., Desai, U., Despande, N., and Yadav, N. (2012). Photodynamic Therapy: A View through Light. Jofr 2, 82-86. doi:10.5005/jp-journals-10026-1019

Davis, A., Tinker, A. V., and Friedlander, M. (2014). "Platinum Resistant" Ovarian Cancer: What Is it, Who to Treat and How to Measure Benefit? Gynecol. Oncol. 133 (3), 624-631. doi:10.1016/j.ygyno.2014.02.038

DeBerardinis, R. J., Lum, J. J., Hatzivassiliou, G., and Thompson, C. B. (2008). The Biology of Cancer: Metabolic Reprogramming Fuels Cell Growth and Proliferation. Cel Metab. 7 (1), 11-20. doi:10.1016/j.cmet.2007.10.002

Dobson, J., de Queiroz, G. F., and Golding, J. P. (2018). Photodynamic Therapy and Diagnosis: Principles and Comparative Aspects. Vet. J. 233, 8-18. doi:10.1016/ j.tvjl.2017.11.012

Doix, B., Trempolec, N., Riant, O., and Feron, O. (2019). Low Photosensitizer Dose and Early Radiotherapy Enhance Antitumor Immune Response of Photodynamic Therapy-Based Dendritic Cell Vaccination. Front. Oncol. 9, 811. doi:10.3389/fonc.2019.00811

Dolmans, D. E. J. G. J., Fukumura, D., and Jain, R. K. (2003). Photodynamic Therapy for Cancer. Nat. Rev. Cancer 3 (5), 380-387. doi:10.1038/nrc1071

Dos Santos, A. 1. F., De Almeida, D. R. Q., Terra, L. F., Baptista, M. c. S., and Labriola, L. (2019). Photodynamic Therapy in Cancer Treatment - an Update Review. Jcmt 2019, 25. doi:10.20517/2394-4722.2018.83

Dougherty, T. J., Gomer, C. J., Henderson, B. W., Jori, G., Kessel, D., Korbelik, M., et al. (1998). Photodynamic Therapy. JNCI J. Natl. Cancer Inst. 90 (12), 889-905. doi:10.1093/jnci/90.12.889

Dougherty, T. J. (1996). A Brief History of Clinical Photodynamic Therapy Development at Roswell Park Cancer Institute. J. Clin. Laser Med. Surg. 14 (5), 219-221. doi:10.1089/clm.1996.14.219

Duan, X., Chan, C., Guo, N., Han, W., Weichselbaum, R. R., and Lin, W. (2016). Photodynamic Therapy Mediated by Nontoxic Core-Shell Nanoparticles Synergizes with Immune Checkpoint Blockade to Elicit Antitumor Immunity and Antimetastatic Effect on Breast Cancer. J. Am. Chem. Soc. 138 (51), 16686-16695. doi:10.1021/jacs.6b09538

Duchi, S., Sotgiu, G., Lucarelli, E., Ballestri, M., Dozza, B., Santi, S., et al. (2013). Mesenchymal Stem Cells as Delivery Vehicle of Porphyrin Loaded Nanoparticles: Effective Photoinduced In Vitro Killing of Osteosarcoma. J. Controlled Release 168 (2), 225-237. doi:10.1016/j.jconrel.2013.03.012

DUSA (2018). Levulan Kerastick (Aminolevulinic Acid HCl) [package Insert]. U.S. Food and Drug Administration Website. Revised April 2018. Available at: https://www.accessdata.fda.gov/drugsatfda_docs/label/2018/020965s016lbl. pdf. (Accessed Mar 14, 2021).

Ebers, G. (1875). Papyros Ebers: Das Hermetische Buch über die Arzneimittel der alten Ägypter in hieratischer Schrift (Band 1): Einleitung und Text. Leipzig: Verlag von Wilhelm Engelmann.

Eccles, S. A. (2011). The Epidermal Growth Factor receptor/Erb-B/HER Family in normal and Malignant Breast Biology. Int. J. Dev. Biol. 55 (7-9), 685-696. doi:10.1387/ijdb.113396se

Eppert, K., Takenaka, K., Lechman, E. R., Waldron, L., Nilsson, B., van Galen, P., et al. (2011). Stem Cell Gene Expression Programs Influence Clinical Outcome in Human Leukemia. Nat. Med. 17 (9), 1086-1093. doi:10.1038/nm.2415

Esim, O., Gedik, M. E., Dogan, A. L., Gunaydin, G., and Hascicek, C. (2021). Development of Carboplatin Loaded Bovine Serum Albumin Nanoparticles and Evaluation of its Effect on an Ovarian Cancer Cell Line. J. Drug Deliv. Sci. Technol. 64, 102655. doi:10.1016/j.jddst.2021.102655

Fan, W., Huang, P., and Chen, X. (2016). Overcoming the Achilles' Heel of Photodynamic Therapy. Chem. Soc. Rev. 45 (23), 6488-6519. doi:10.1039/ c6cs00616g

Fasiku, V., K. Amuhaya, E., M. Rajab, K., and A. Omolo, C. (2021, Nano/ Microparticles Encapsulation via Covalent Drug Conjugation London, UK: IntechOpen. doi:10.5772/intechopen.93364

Ferrario, A., and Gomer, C. (2006). Avastin Enhances Photodynamic Therapy Treatment of Kaposi's Sarcoma in a Mouse Tumor Model. J. Environ. Pathol. Toxicol. Oncol. 25 (1-2), 251-260. doi:10.1615/jenvironpatholtoxicoloncol.v25.11-2.160

Ferrario, A., von Tiehl, K. F., Rucker, N., Schwarz, M. A., Gill, P. S., and Gomer, C. J. (2000). Antiangiogenic Treatment Enhances Photodynamic Therapy Responsiveness in a Mouse Mammary Carcinoma. Cancer Res. 60 (15), 4066-4069. 
Firczuk, M., Winiarska, M., Szokalska, A., Jodlowska, M., Swiech, M., Bojarczuk, K., et al. (2011). Approaches to Improve Photodynamic Therapy of Cancer. Front. Biosci. 16, 208-224. doi:10.2741/3684

Fitzpatrick, T. B., and Pathak, M. A. (1959). Part IV: Basic Considerations of the Psoralens: Historical Aspects of Methoxsalen and Other Furocoumarins11From the Division of Dermatology, University of Oregon Medical School, Portland, Oregon. J. Invest. Dermatol. 32 (2), 229-231. doi:10.1038/jid.1959.40

Fleshker, S., Preise, D., Kalchenko, V., Scherz, A., and Salomon, Y. (2008). Prompt Assessment of WST11-VTP Outcome Using Luciferase Transfected Tumors Enables Second Treatment and Increase in Overall Therapeutic Rate. Photochem. Photobiol. 84 (5), 1231-1237. doi:10.1111/j.17511097.2008.00340.x

Freitas, L. F., and Hamblin, M. (2016). Chapter 1 - Antimicrobial Photoinactivation with Functionalized Fullerenes. Nanobiomater. Antimicrob. Ther., 1-27. doi:10.1016/b978-0-323-42864-4.00001-4

Friedberg, J. S., Mick, R., Stevenson, J., Metz, J., Zhu, T., Buyske, J., et al. (2003). A Phase I Study of Foscan-Mediated Photodynamic Therapy and Surgery in Patients with Mesothelioma. Ann. Thorac. Surg. 75 (3), 952-959. doi:10.1016/ s0003-4975(02)04474-0

Friedberg, J. S., Mick, R., Stevenson, J. P., Zhu, T., Busch, T. M., Shin, D., et al. (2004). Phase II Trial of Pleural Photodynamic Therapy and Surgery for Patients with Non-small-cell Lung Cancer with Pleural Spread. Jco 22 (11), 2192-2201. doi:10.1200/JCO.2004.07.097

Fukuhara, H., Yamamoto, S., Karashima, T., and Inoue, K. (2021). Photodynamic Diagnosis and Therapy for Urothelial Carcinoma and Prostate Cancer: New Imaging Technology and Therapy. Int. J. Clin. Oncol. 26 (1), 18-25. doi:10.1007/s10147-020-01704-y

Furuse, K., Fukuoka, M., Kato, H., Horai, T., Kubota, K., Kodama, N., et al. (1993). A Prospective Phase II Study on Photodynamic Therapy with Photofrin II for Centrally Located Early-Stage Lung Cancer. The Japan Lung Cancer Photodynamic Therapy Study Group. Jco 11 (10), 1852-1857. doi:10.1200/ JCO.1993.11.10.1852

Galderma Labs LP (2012). Gleolan (Aminolevulinic Acid Hydrochloride) [package Insert]. U.S. Food and Drug Administration Website. Revised November 2012. Available at: https://www.accessdata.fda.gov/drugsatfda_docs/label/2012/ 021415s004lbl.pdf. (Accessed Mar 14, 2021).

Gan, J., Li, S., Meng, Y., Liao, Y., Jiang, M., Qi, L., et al. (2020). The Influence of Photodynamic Therapy on the Warburg Effect in Esophageal Cancer Cells. Lasers Med. Sci. 35 (8), 1741-1750. doi:10.1007/s10103-020-02966-8

Garcia-Zuazaga, J., Cooper, K. D., and Baron, E. D. (2005). Photodynamic Therapy in Dermatology: Current Concepts in the Treatment of Skin Cancer. Expert Rev. Anticancer Ther. 5 (5), 791-800. doi:10.1586/14737140.5.5.791

Garg, A. D., Vandenberk, L., Koks, C., Verschuere, T., Boon, L., Van Gool, S. W., et al. (2016). Dendritic Cell Vaccines Based on Immunogenic Cell Death Elicit Danger Signals and T Cell-Driven Rejection of High-Grade Glioma. Sci. Transl. Med. 8 (328), 328ra27. doi:10.1126/scitranslmed.aae0105

Gatenby, R. A., and Gillies, R. J. (2004). Why Do Cancers Have High Aerobic Glycolysis? Nat. Rev. Cancer 4 (11), 891-899. doi:10.1038/nrc1478

Gheewala, T., Skwor, T., and Munirathinam, G. (2017). Photosensitizers in Prostate Cancer Therapy. Oncotarget 8 (18), 30524-30538. doi:10.18632/ oncotarget.15496

Gilkes, D. M., Semenza, G. L., and Wirtz, D. (2014). Hypoxia and the Extracellular Matrix: Drivers of Tumour Metastasis. Nat. Rev. Cancer 14 (6), 430-439. doi: $10.1038 / \mathrm{nrc} 3726$

Gillet, J.-P., and Gottesman, M. M. (2010). Mechanisms of Multidrug Resistance in Cancer. Methods Mol. Biol. 596, 47-76. doi:10.1007/978-1-60761-416-6_4

Gogvadze, V., Orrenius, S., and Zhivotovsky, B. (2008). Mitochondria in Cancer Cells: what Is So Special about Them? Trends Cel Biol. 18 (4), 165-173. doi:10.1016/j.tcb.2008.01.006

Gok Yavuz, B., Gunaydin, G., Gedik, M. E., Kosemehmetoglu, K., Karakoc, D., Ozgur, F., et al. (2019). Cancer Associated Fibroblasts Sculpt Tumour Microenvironment by Recruiting Monocytes and Inducing Immunosuppressive PD-1+ TAMs. Sci. Rep. 9 (1), 3172. doi:10.1038/s41598-019-39553-Z

Goldberg, B. (1930). Heliotherapy. Arch. Phys. Ther. 11, 263.

Gollnick, S. O., Vaughan, L., and Henderson, B. W. (2002). Generation of Effective Antitumor Vaccines Using Photodynamic Therapy. Cancer Res. 62 (6), 1604-1608.
Gomer, C. J. (1991). Preclinical Examination of First and Second Generation Photosensitizers Used in Photodynamic Therapy. Photochem. Photobiol. 54 (6), 1093-1107. doi:10.1111/j.1751-1097.1991.tb02133.x

Gonzalez, H., Hagerling, C., and Werb, Z. (2018). Roles of the Immune System in Cancer: from Tumor Initiation to Metastatic Progression. Genes Dev. 32 (1920), 1267-1284. doi:10.1101/gad.314617.118

Green, D. R., Ferguson, T., Zitvogel, L., and Kroemer, G. (2009). Immunogenic and Tolerogenic Cell Death. Nat. Rev. Immunol. 9 (5), 353-363. doi:10.1038/ nri2545

Gross, S., Gilead, A., Scherz, A., Neeman, M., and Salomon, Y. (2003). Monitoring Photodynamic Therapy of Solid Tumors Online by BOLD-Contrast MRI. Nat. Med. 9 (10), 1327-1331. doi:10.1038/nm940

Grzybowski, A., Sak, J., and Pawlikowski, J. (2016). A Brief Report on the History of Phototherapy. Clin. Dermatol. 34 (5), 532-537. doi:10.1016/ j.clindermatol.2016.05.002

Gunaydin, G., and Gedik, M. E. (2019). Effects of Cellular Energy Homeostasis Modulation through AMPK on Regulation of Protein Translation and Response to Hypoxia. Turkish J. Biochem. 44 (5), 611-620. doi:10.1515/tjb2018-0338

Gunaydin, G., Kesikli, S. A., and Guc, D. (2015). Cancer Associated Fibroblasts Have Phenotypic and Functional Characteristics Similar to the Fibrocytes that Represent a Novel MDSC Subset. Oncoimmunology 4 (9), e1034918. doi:10.1080/2162402X.2015.1034918

Gunaydin, G., Gedik, M. E., and Ayan, S. (2021). Photodynamic Therapy-Current Limitations and Novel Approaches. Front. Chem. 9, 691697. doi:10.3389/ fchem.2021.691697

Gunaydin, G. (2021). CAFs Interacting with TAMs in Tumor Microenvironment to Enhance Tumorigenesis and Immune Evasion. Front. Oncol. 11. doi:10.3389/ fonc.2021.668349

Gupta, S., Mishra, A. K., Muralidhar, K., and Jain, V. (2004). Improved Targeting of Photosensitizers by Intratumoral Administration of Immunoconjugates. Technol. Cancer Res. Treat. 3 (3), 295-301. doi:10.1177/153303460400300307

Haider, M. A., Davidson, S. R. H., Kale, A. V., Weersink, R. A., Evans, A. J., Toi, A., et al. (2007). Prostate Gland: MR Imaging Appearance after Vascular Targeted Photodynamic Therapy with Palladium-Bacteriopheophorbide. Radiology 244 (1), 196-204. doi:10.1148/radiol.2441060398

Hamblin, M. R., and Hasan, T. (2004). Photodynamic Therapy: a New Antimicrobial Approach to Infectious Disease? Photochem. Photobiol. Sci. 3 (5), 436-450. doi:10.1039/b311900a

Hamblin, M. R. (2018). Fullerenes as Photosensitizers in Photodynamic Therapy: Pros and Cons. Photochem. Photobiol. Sci. 17 (11), 1515-1533. doi:10.1039/ c8pp00195b

Han, Y., Liu, D., and Li, L. (2020). PD-1/PD-L1 Pathway: Current Researches in Cancer. Am. J. Cancer Res. 10 (3), 727-742.

Hartmann, A. (2016). Back to the Roots - Dermatology in Ancient Egyptian Medicine. JDDG: J. der Deutschen Dermatologischen Gesellschaft 14 (4), 389-396. doi:10.1111/ddg.12947

He, C., Duan, X., Guo, N., Chan, C., Poon, C., Weichselbaum, R. R., et al. (2016), Core-shell Nanoscale Coordination Polymers Combine Chemotherapy and Photodynamic Therapy to Potentiate Checkpoint Blockade Cancer Immunotherapy. Nat. Commun. 7, 12499. doi:10.1038/ncomms 12499

Hefti, M., Maximilian Mehdorn, H., Albert, I., and Dorner, L. (2010). Fluorescence-Guided Surgery for Malignant Glioma: A Review on Aminolevulinic Acid Induced Protoporphyrin IX Photodynamic Diagnostic in Brain Tumors. Cmir 6 (4), 254-258. doi:10.2174/157340510793205503

Hester, S. C., Kuriakose, M., Nguyen, C. D., and Mallidi, S. (2020). Role of Ultrasound and Photoacoustic Imaging in Photodynamic Therapy for Cancer. Photochem. Photobiol. 96 (2), 260-279. doi:10.1111/php.13217

Hiam-Galvez, K. J., Allen, B. M., and Spitzer, M. H. (2021). Systemic Immunity in Cancer. Nat. Rev. Cancer 21 (6), 345-359. doi:10.1038/s41568-021-00347-z

Hodgkinson, N., Kruger, C. A., and Abrahamse, H. (2017). Targeted Photodynamic Therapy as Potential Treatment Modality for the Eradication of colon Cancer and colon Cancer Stem Cells. Tumour Biol. 39 (10), 101042831773469. doi:10.1177/1010428317734691

Hönigsmann, H. (2013). History of Phototherapy in Dermatology. Photochem. Photobiol. Sci. 12 (1), 16-21. doi:10.1039/c2pp25120e

Huang, Z., Haider, M. A., Kraft, S., Chen, Q., Blanc, D., Wilson, B. C., et al. (2006). Magnetic Resonance Imaging Correlated with the Histopathological Effect of 
Pd-Bacteriopheophorbide (Tookad) Photodynamic Therapy on the normal Canine Prostate Gland. Lasers Surg. Med. 38 (7), 672-681. doi:10.1002/ lsm. 20375

Huang, Z. (2005). A Review of Progress in Clinical Photodynamic Therapy. Technol. Cancer Res. Treat. 4 (3), 283-293. doi:10.1177/153303460500400308

Hudson, R., Carcenac, M., Smith, K., Madden, L., Clarke, O. J., Pèlegrin, A., et al. (2005). The Development and Characterisation of Porphyrin IsothiocyanateMonoclonal Antibody Conjugates for Photoimmunotherapy. Br. J. Cancer 92 (8), 1442-1449. doi:10.1038/sj.bjc.6602517

Huggett, M. T., Jermyn, M., Gillams, A., Illing, R., Mosse, S., Novelli, M., et al. (2014). Phase I/II Study of Verteporfin Photodynamic Therapy in Locally Advanced Pancreatic Cancer. Br. J. Cancer 110 (7), 1698-1704. doi:10.1038/ bjc. 2014.95

Inoue, K. (2017). 5-Aminolevulinic Acid-Mediated Photodynamic Therapy for Bladder Cancer. Int. J. Urol. 24 (2), 97-101. doi:10.1111/iju.13291

Iqbal, N., and Iqbal, N. (2014). Human Epidermal Growth Factor Receptor 2 (HER2) in Cancers: Overexpression and Therapeutic Implications. Mol. Biol. Int. 2014, 1-9. doi:10.1155/2014/852748

Islam, F., Qiao, B., Smith, R. A., Gopalan, V., and Lam, A. K.-Y. (2015). Cancer Stem Cell: Fundamental Experimental Pathological Concepts and Updates. Exp. Mol. Pathol. 98 (2), 184-191. doi:10.1016/j.yexmp.2015.02.002

Jalili, A., Makowski, M., Świtaj, T., Nowis, D., Wilczyński, G. M., Wilczek, E., et al. (2004). Effective Photoimmunotherapy of Murine colon Carcinoma Induced by the Combination of Photodynamic Therapy and Dendritic Cells. Clin. Cancer Res. 10 (13), 4498-4508. doi:10.1158/1078-0432.CCR-04-0367

Jankun, J., Keck, R. W., Skrzypczak-Jankun, E., Lilge, L., and Selman, S. H. (2005). Diverse Optical Characteristic of the Prostate and Light Delivery System: Implications for Computer Modelling of Prostatic Photodynamic Therapy. BJU Int. 95 (9), 1237-1244. doi:10.1111/j.1464-410X.2005.05512.x

Jiang, F., Zhang, X., Kalkanis, S. N., Zhang, Z., Yang, H., Katakowski, M., et al. (2008). Combination Therapy with Antiangiogenic Treatment and Photodynamic Therapy for the Nude Mouse Bearing U87 Glioblastoma. Photochem. Photobiol. 84 (1), 128-137. doi:10.1111/j.1751-1097.2007.00208.x

Jin, M.-Z., and Jin, W.-L. (2020). The Updated Landscape of Tumor Microenvironment and Drug Repurposing. Sig Transduct Target. Ther. 5 (1), 166. doi:10.1038/s41392-020-00280-x

Jin, M. L., Yang, B. Q., Zhang, W., and Ren, P. (1992). Combined Treatment with Photodynamic Therapy and Chemotherapy for Advanced Cardiac Cancers. J. Photochem. Photobiol. B: Biol. 12 (1), 101-106. doi:10.1016/1011-1344(92) $85021-1$

Jori, G., Fabris, C., Soncin, M., Ferro, S., Coppellotti, O., Dei, D., et al. (2006). Photodynamic Therapy in the Treatment of Microbial Infections: Basic Principles and Perspective Applications. Lasers Surg. Med. 38 (5), 468-481. doi:10.1002/lsm.20361

Jori, G. (2006). Photodynamic Therapy of Microbial Infections: State of the Art and Perspectives. J. Environ. Pathol. Toxicol. Oncol. 25 (1-2), 505-520. doi:10.1615/ jenvironpatholtoxicoloncol.v25.11-2.320

Josefsen, L. B., and Boyle, R. W. (2008). Photodynamic Therapy: Novel ThirdGeneration Photosensitizers One Step Closer? Br. J. Pharmacol. 154 (1), 1-3. doi:10.1038/bjp.2008.98

Juarranz, Á., Jaén, P., Sanz-Rodríguez, F., Cuevas, J., and González, S. (2008). Photodynamic Therapy of Cancer. Basic Principles and Applications. Clin. Transl Oncol. 10 (3), 148-154. doi:10.1007/s12094-008-0172-2

Juzeniene, A., Peng, Q., and Moan, J. (2007). Milestones in the Development of Photodynamic Therapy and Fluorescence Diagnosis. Photochem. Photobiol. Sci. 6 (12), 1234-1245. doi:10.1039/b705461k

Kallioniemi, O. P., Kallioniemi, A., Kurisu, W., Thor, A., Chen, L. C., Smith, H. S., et al. (1992). ERBB2 Amplification in Breast Cancer Analyzed by Fluorescence In Situ Hybridization. Proc. Natl. Acad. Sci. 89 (12), 5321-5325. doi:10.1073/ pnas.89.12.5321

Karaman, O., Almammadov, T., Emre Gedik, M., Gunaydin, G., Kolemen, S., and Gunbas, G. (2019). Mitochondria-Targeting Selenophene-Modified BODIPYBased Photosensitizers for the Treatment of Hypoxic Cancer Cells. ChemMedChem 14 (22), 1879-1886. doi:10.1002/cmdc.201900380

Karges, J., Tharaud, M., and Gasser, G. (2021). Polymeric Encapsulation of a $\mathrm{Ru}$ (II)-Based Photosensitizer for Folate-Targeted Photodynamic Therapy of Drug Resistant Cancers. J. Med. Chem. 64 (8), 4612-4622. doi:10.1021/ acs.jmedchem.0c02006
Kästle, M., Grimm, S., Nagel, R., Breusing, N., and Grune, T. (2011). Combination of PDT and Inhibitor Treatment Affects Melanoma Cells and Spares Keratinocytes. Free Radic. Biol. Med. 50 (2), 305-312. doi:10.1016/ j.freeradbiomed.2010.11.012

Kataoka, H., Nishie, H., Hayashi, N., Tanaka, M., Nomoto, A., Yano, S., et al. (2017). New Photodynamic Therapy with Next-Generation Photosensitizers. Ann. Transl. Med. 5 (8), 183. doi:10.21037/atm.2017.03.59

Kato, H. (2004). The History of the Study of Photodynamic Therapy (PDT) and Photodynamic Diagnosis (PDD) in the Department of Surgery, Tokyo Medical University. Photodiagn. Photodyn. Ther. 1, 107-110. doi:10.1016/s15721000(04)00044-4

Kausch, I., Sommerauer, M., Montorsi, F., Stenzl, A., Jacqmin, D., Jichlinski, P., et al. (2010). Photodynamic Diagnosis in Non-muscle-invasive Bladder Cancer: a Systematic Review and Cumulative Analysis of Prospective Studies. Eur. Urol. 57 (4), 595-606. doi:10.1016/j.eururo.2009.11.041

Kawczyk-Krupka, A., Bugaj, A. M., Latos, W., Zaremba, K., Wawrzyniec, K., and Sieroń, A. (2015). Photodynamic Therapy in Colorectal Cancer Treatment: the State of the Art in Clinical Trials. Photodiagn. Photodyn. Ther. 12 (3), 545-553. doi:10.1016/j.pdpdt.2015.04.004

Khdair, A., Di Chen, D., Patil, Y., Ma, L., Dou, Q. P., Shekhar, M. P. V., et al. (2010). Nanoparticle-mediated Combination Chemotherapy and Photodynamic Therapy Overcomes Tumor Drug Resistance. J. Controlled Release 141 (2), 137-144. doi:10.1016/j.jconrel.2009.09.004

Kim, H.-I., and Wilson, B. C. (2020). Photodynamic Diagnosis and Therapy for Peritoneal Carcinomatosis from Gastrointestinal Cancers: Status, Opportunities, and Challenges. J. Gastric Cancer 20 (4), 355-375. doi:10.5230/jgc.2020.20.e39

Kimani, S. G., Phillips, J. B., Bruce, J. I., MacRobert, A. J., and Golding, J. P. (2012). Antioxidant Inhibitors Potentiate the Cytotoxicity of Photodynamic Therapy. Photochem. Photobiol. 88 (1), 175-187. doi:10.1111/j.17511097.2011.01022.x

Kleinovink, J. W., Fransen, M. F., Löwik, C. W., and Ossendorp, F. (2017). Photodynamic-Immune Checkpoint Therapy Eradicates Local and Distant Tumors by CD8+ T Cells. Cancer Immunol. Res. 5 (10), 832-838. doi:10.1158/2326-6066.CIR-17-0055

Korbelik, M., and Sun, J. (2006). Photodynamic Therapy-Generated Vaccine for Cancer Therapy. Cancer Immunol. Immunother. 55 (8), 900-909. doi:10.1007/ s00262-005-0088-4

Korbelik, M., Stott, B., and Sun, J. (2007). Photodynamic Therapy-Generated Vaccines: Relevance of Tumour Cell Death Expression. Br. J. Cancer 97 (10), 1381-1387. doi:10.1038/sj.bjc.6604059

Korbelik, M., Banáth, J., Zhang, W., Gallagher, P., Hode, T., Lam, S. S. K., et al. (2019). N-dihydrogalactochitosan as Immune and Direct Antitumor Agent Amplifying the Effects of Photodynamic Therapy and Photodynamic TherapyGenerated Vaccines. Int. Immunopharmacology 75, 105764. doi:10.1016/ j.intimp.2019.105764

Korbelik, M. (2010). Photodynamic Therapy-Generated Cancer Vaccines. Methods Mol. Biol. 635, 147-153. doi:10.1007/978-1-60761-697-9_11

Korbelik, M. (2019). Cancer PDT Vaccines: Progress and Prospects (Conference Presentation). Bellingham, Washington: SPIE.

Kou, J., Dou, D., and Yang, L. (2017). Porphyrin Photosensitizers in Photodynamic Therapy and its Applications. Oncotarget 8 (46), 81591-81603. doi:10.18632/ oncotarget.20189

Kreso, A., and Dick, J. E. (2014). Evolution of the Cancer Stem Cell Model. Cell Stem Cell 14 (3), 275-291. doi:10.1016/j.stem.2014.02.006

Kroemer, G., Galluzzi, L., Kepp, O., and Zitvogel, L. (2013). Immunogenic Cell Death in Cancer Therapy. Annu. Rev. Immunol. 31, 51-72. doi:10.1146/ annurev-immunol-032712-100008

Kuijpers, D. I. M., Smeets, N. W. J., Krekels, G. A. M., and Thissen, M. R. T. M. (2004). Photodynamic Therapy as Adjuvant Treatment of Extensive Basal Cell Carcinoma Treated with Mohs Micrographic Surgery. Dermatol. Surg. 30 (5), 794-798. doi:10.1111/j.1524-4725.2004.30221.x

Kuo, W.-S., Chang, C.-N., Chang, Y.-T., Yang, M.-H., Chien, Y.-H., Chen, S.-J., et al. (2010). Gold Nanorods in Photodynamic Therapy, as Hyperthermia Agents, and in Near-Infrared Optical Imaging. Angew. Chem. Int. Edition 49 (15), 2711-2715. doi:10.1002/anie.200906927

Kwiatkowski, S., Knap, B., Przystupski, D., Saczko, J., Kędzierska, E., Knap-Czop, K., et al. (2018). Photodynamic Therapy - Mechanisms, Photosensitizers and 
Combinations. Biomed. Pharmacother. 106, 1098-1107. doi:10.1016/ j.biopha.2018.07.049

Kwitniewski, M., Juzeniene, A., Glosnicka, R., and Moan, J. (2008). Immunotherapy: a Way to Improve the Therapeutic Outcome of Photodynamic Therapy? Photochem. Photobiol. Sci. 7 (9), 1011-1017. doi:10.1039/b806710d

Labani-Motlagh, A., Ashja-Mahdavi, M., and Loskog, A. (2020). The Tumor Microenvironment: A Milieu Hindering and Obstructing Antitumor Immune Responses. Front. Immunol. 11, 940. doi:10.3389/fimmu.2020.00940

Lan, M., Zhao, S., Zhang, Z., Yan, L., Guo, L., Niu, G., et al. (2017). Two-photonexcited Near-Infrared Emissive Carbon Dots as Multifunctional Agents for Fluorescence Imaging and Photothermal Therapy. Nano Res. 10 (9), 3113-3123. doi:10.1007/s12274-017-1528-0

Lan, G., Ni, K., Xu, Z., Veroneau, S. S., Song, Y., and Lin, W. (2018). Nanoscale Metal-Organic Framework Overcomes Hypoxia for Photodynamic Therapy Primed Cancer Immunotherapy. J. Am. Chem. Soc. 140 (17), 5670-5673. doi:10.1021/jacs.8b01072

Lee, H. M., Jeong, Y.-I., Kim, D. H., Kwak, T. W., Chung, C.-W., Kim, C. H., et al. (2013). Ursodeoxycholic Acid-Conjugated Chitosan for Photodynamic Treatment of HuCC-T1 Human Cholangiocarcinoma Cells. Int. J. Pharmaceutics 454 (1), 74-81. doi:10.1016/j.ijpharm.2013.06.035

Li, L.-B., and Luo, R.-C. (2009). Effect of Drug-Light Interval on the Mode of Action of Photofrin Photodynamic Therapy in a Mouse Tumor Model. Lasers Med. Sci. 24 (4), 597-603. doi:10.1007/s10103-008-0620-9

Li, L.-b., Luo, R.-c., Liao, W.-j., Zhang, M.-j., Luo, Y.-l., and Miao, J.-x. (2006). Clinical Study of Photofrin Photodynamic Therapy for the Treatment of Relapse Nasopharyngeal Carcinoma. Photodiagn. Photodyn. Ther. 3 (4), 266-271. doi:10.1016/j.pdpdt.2006.09.004

Li, D., Zhang, F., Shi, L., Lin, L., Cai, Q., and Xu, Y. (2020a). Treatment of HPV Infection-Associated Low Grade Cervical Intraepithelial Neoplasia with 5Aminolevulinic Acid-Mediated Photodynamic Therapy. Photodiagn. Photodyn. Ther. 32, 101974. doi:10.1016/j.pdpdt.2020.101974

Li, X., Lovell, J. F., Yoon, J., and Chen, X. (2020b). Clinical Development and Potential of Photothermal and Photodynamic Therapies for Cancer. Nat. Rev. Clin. Oncol. 17 (11), 657-674. doi:10.1038/s41571-020-0410-2

Li, W.-P., Yen, C.-J., Wu, B.-S., and Wong, T.-W. (2021). Recent Advances in Photodynamic Therapy for Deep-Seated Tumors with the Aid of Nanomedicine. Biomedicines 9 (1), 69. doi:10.3390/biomedicines9010069

Liang, C., Zhang, X., Yang, M., Wang, W., Chen, P., and Dong, X. (2020). Remodeling Tumor Microenvironment by Multifunctional Nanoassemblies for Enhanced Photodynamic Cancer Therapy. ACS Mater. Lett. 2 (10), 1268-1286. doi:10.1021/acsmaterialslett.0c00259

Lipson, R. L., and Baldes, E. J. (1960). The Photodynamic Properties of a Particular Hematoporphyrin Derivative. Arch. Dermatol. 82, 508-516. doi:10.1001/ archderm.1960.01580040026005

Lipson, R. L., Baldes, E. J., and Olsen, A. M. (1961). Hematoporphyrin Derivative: a New Aid for Endoscopic Detection of Malignant Disease. J. Thorac. Cardiovasc. Surg. 42 (5), 623-629. doi:10.1016/S0022-5223(19)32560-7

Lipson, R. L., Baldes, E. J., and Gray, M. J. (1967). Hematoporphyrin Derivative for Detection and Management of Cancer. Cancer 20 (12), 2255-2257. doi:10.1002/ 1097-0142(196712)20:12<2255::aid-cncr2820201229>3.0.co;2-u

Liu, Z., Xie, Z., Li, W., Wu, X., Jiang, X., Li, G., et al. (2021). Photodynamic Immunotherapy of Cancers Based on Nanotechnology: Recent Advances and Future Challenges. J. Nanobiotechnol 19 (1), 160. doi:10.1186/s12951-02100903-7

Los, M., Roodhart, J. M. L., and Voest, E. E. (2007). Target Practice: Lessons from Phase III Trials with Bevacizumab and Vatalanib in the Treatment of Advanced Colorectal Cancer. Oncologist 12 (4), 443-450. doi:10.1634/theoncologist.12$4-443$

Lotfinejad, P., Kazemi, T., Mokhtarzadeh, A., Shanehbandi, D., Jadidi Niaragh, F., Safaei, S., et al. (2020). PD-1/PD-L1 axis Importance and Tumor Microenvironment Immune Cells. Life Sci. 259, 118297. doi:10.1016/j.lfs.2020.118297

Loveday, C., Litchfield, K., Proszek, P. Z., Cornish, A. J., Santo, F., Levy, M., et al. (2020). Genomic Landscape of Platinum Resistant and Sensitive Testicular Cancers. Nat. Commun. 11 (1), 2189. doi:10.1038/s41467-020-15768-x

Lu, K., He, C., and Lin, W. (2015). A Chlorin-Based Nanoscale Metal-Organic Framework for Photodynamic Therapy of Colon Cancers. J. Am. Chem. Soc. 137 (24), 7600-7603. doi:10.1021/jacs.5b04069
Lu, K., He, C., Guo, N., Chan, C., Ni, K., Weichselbaum, R. R., et al. (2016). Chlorin-Based Nanoscale Metal-Organic Framework Systemically Rejects Colorectal Cancers via Synergistic Photodynamic Therapy and Checkpoint Blockade Immunotherapy. J. Am. Chem. Soc. 138 (38), 12502-12510. doi:10.1021/jacs.6b06663

Luan, S., Tran, N. T., Xue, H.-Y., and Wong, H.-L. (2021). Development of a High Payload, Cancer-Targeting Liposomes of Methyl Aminolevulinate for Intraoperative Photodynamic Diagnosis/therapy of Peritoneal Carcinomatosis. Int. J. Pharmaceutics 602, 120612. doi:10.1016/ j.jpharm.2021.120612

Luksiene, Z., Kalvelyte, A., and Supino, R. (1999). On the Combination of Photodynamic Therapy with Ionizing Radiation. J. Photochem. Photobiol. B 52 (1-3), 35-42. doi:10.1016/s1011-1344(99)00098-6

Luo, S., Zhang, E., Su, Y., Cheng, T., and Shi, C. (2011). A Review of NIR Dyes in Cancer Targeting and Imaging. Biomaterials 32 (29), 7127-7138. doi:10.1016/ j.biomaterials.2011.06.024

Ma, L., Iani, V., and Moan, J. (1993). Combination Therapy: Photochemotherapy; Electric Current; and Ionizing Radiation. Different Combinations Studied in a WiDr Human colon Adenocarcinoma Cell Line. J. Photochem. Photobiol. B 21 (2-3), 149-154. doi:10.1016/1011-1344(93)80177-b

Ma, L. W., Berg, K., Danielsen, H. E., Kaalhus, O., Iani, V., and Moan, J. (1996). Enhanced Antitumour Effect of Photodynamic Therapy by Microtubule Inhibitors. Cancer Lett. 109 (1-2), 129-139. doi:10.1016/s0304-3835(96) 04437-0

MacCormack, M. A. (2006). Photodynamic Therapy. Adv. Dermatol. 22, 219-258. doi:10.1016/j.yadr.2006.09.008

Maeding, N., Verwanger, T., and Krammer, B. (2016). Boosting Tumor-Specific Immunity Using PDT. Cancers 8 (10), 91. doi:10.3390/cancers8100091

Majidinia, M., Mirza-Aghazadeh-Attari, M., Rahimi, M., Mihanfar, A., Karimian, A., Safa, A., et al. (2020). Overcoming Multidrug Resistance in Cancer: Recent Progress in Nanotechnology and New Horizons. IUBMB Life 72 (5), 855-871. doi:10.1002/iub.2215

McDonagh, A. F. (2001). Phototherapy: from Ancient Egypt to the New Millennium. J. Perinatol 21 (Suppl. 1), S7-S12. doi:10.1038/sj.jp.7210625

Meng, Z., Zhou, X., Xu, J., Han, X., Dong, Z., Wang, H., et al. (2019). LightTriggered In Situ Gelation to Enable Robust Photodynamic-Immunotherapy by Repeated Stimulations. Adv. Mater. 31 (24), 1900927. doi:10.1002/ adma.201900927

Merriam-Webster (2021). Atharva Veda [Online]. Merriam-Webster.Com Dictionary. Available: https://www.merriam-webster.com/dictionary/Atharva \%20Veda. (Accessed Jun 28, 2021).

Mfouo-Tynga, I. S., Dias, L. D., Inada, N. M., and Kurachi, C. (2021). Features of Third Generation Photosensitizers Used in Anticancer Photodynamic Therapy: Review. Photodiagnosis Photodynamic Ther. 34, 102091. doi:10.1016/ j.pdpdt.2020.102091

Millington, G. W. M., and Levell, N. J. (2007). Vitiligo: the Historical Curse of Depigmentation. Int. J. Dermatol. 46 (9), 990-995. doi:10.1111/j.13654632.2007.03195.x

Mitchell, M. J., Billingsley, M. M., Haley, R. M., Wechsler, M. E., Peppas, N. A., and Langer, R. (2021). Engineering Precision Nanoparticles for Drug Delivery. Nat. Rev. Drug Discov. 20 (2), 101-124. doi:10.1038/s41573-020-0090-8

Mitton, D., and Ackroyd, R. (2008). A Brief Overview of Photodynamic Therapy in Europe. Photodiagnosis Photodynamic Ther. 5 (2), 103-111. doi:10.1016/ j.pdpdt.2008.04.004

Moan, J., and Berg, K. (1991). The Photodegradation of Porphyrins in Cells Can Be Used to Estimate the Lifetime of Singlet Oxygen. Photochem. Photobiol. 53 (4), 549-553. doi:10.1111/j.1751-1097.1991.tb03669.x

Moan, J. (1986). Porphyrin Photosensitization and Phototherapy. Photochem. Photobiol. 43 (6), 681-690. doi:10.1111/j.1751-1097.1986.tb05647.x

Moon, Y. W., Hajjar, J., Hwu, P., and Naing, A. (2015). Targeting the Indoleamine 2,3-dioxygenase Pathway in Cancer. J. Immunotherapy Cancer 3, 51. doi:10.1186/s40425-015-0094-9

Moore, C. M., Pendse, D., and Emberton, M. (2009). Photodynamic Therapy for Prostate Cancer-A Review of Current Status and Future Promise. Nat. Rev. Urol. 6 (1), 18-30. doi:10.1038/ncpuro1274

Moore, C. M., Emberton, M., and Bown, S. G. (2011). Photodynamic Therapy for Prostate Cancer-An Emerging Approach for Organ-Confined Disease. Lasers Surg. Med. 43 (7), 768-775. doi:10.1002/lsm.21104 
Moser, J. G. (1998). Photodynamic Tumor Therapy: 2nd and 3rd Generation Photosensitizers. Amsterdam: Harwood Academic Publishers.

Mowatt, G., N'Dow, J., Vale, L., Nabi, G., Boachie, C., Cook, J. A., et al. (2011). Photodynamic Diagnosis of Bladder Cancer Compared with white Light Cystoscopy: Systematic Review and Meta-Analysis. Int. J. Technol. Assess. Health Care 27 (1), 3-10. doi:10.1017/S0266462310001364

Murata, K., Tsukahara, T., and Torigoe, T. (2016). Cancer Immunotherapy and Immunological Memory. Jpn. J. Clin. Immunol. 39 (1), 18-22. doi:10.2177/ jsci.39.18

Nahabedian, M. Y., Cohen, R. A., Contino, M. F., Terem, T. M., Wright, W. H., Berns, M. W., et al. (1988). Combination Cytotoxic Chemotherapy With Cisplatin or Doxorubicin and Photodynamic Therapy in Murine Tumors1. JNCI J. Natl. Cancer Inst. 80 (10), 739-743. doi:10.1093/jnci/80.10.739

Nakano, A., Watanabe, D., Akita, Y., Kawamura, T., Tamada, Y., and Matsumoto, Y. (2011). Treatment Efficiency of Combining Photodynamic Therapy and Ionizing Radiation for Bowen's Disease. J. Eur. Acad. Dermatol. Venereol. 25 (4), 475-478. doi:10.1111/j.1468-3083.2010.03757.x

Nanashima, A., Yamaguchi, H., Shibasaki, S., Ide, N., Sawai, T., Tsuji, T., et al. (2004). Adjuvant Photodynamic Therapy for Bile Duct Carcinoma after Surgery: a Preliminary Study. J. Gastroenterol. 39 (11), 1095-1101. doi:10.1007/s00535-004-1449-z

Narumi, A., Tsuji, T., Shinohara, K., Yamazaki, H., Kikuchi, M., Kawaguchi, S., et al. (2016). Maltotriose-conjugation to a Fluorinated Chlorin Derivative Generating a PDT Photosensitizer with Improved Water-Solubility. Org. Biomol. Chem. 14 (14), 3608-3613. doi:10.1039/c6ob00276e

Naylor, M. F., Chen, W. R., Teague, T. K., Perry, L. A., and Nordquist, R. E. (2006). In Situ photoimmunotherapy: a Tumour-Directed Treatment for Melanoma. Br. J. Dermatol. 155 (6), 1287-1292. doi:10.1111/j.1365-2133.2006.07514.x

Ng, C. W., Li, J., and Pu, K. (2018). Recent Progresses in Phototherapy-Synergized Cancer Immunotherapy. Adv. Funct. Mater. 28 (46), 1804688. doi:10.1002/ adfm. 201804688

Niculescu, A.-G., and Grumezescu, A. M. (2021). Photodynamic Therapy-An UpTo-Date Review. Appl. Sci. 11 (8), 3626. doi:10.3390/app11083626

Nishie, H., Kataoka, H., Yano, S., Kikuchi, J.-i., Hayashi, N., Narumi, A., et al. (2016). A Next-Generation Bifunctional Photosensitizer with Improved WaterSolubility for Photodynamic Therapy and Diagnosis. Oncotarget 7 (45), 74259-74268. doi:10.18632/oncotarget.12366

Nishiyama, N., Morimoto, Y., Jang, W.-D., and Kataoka, K. (2009). Design and Development of Dendrimer Photosensitizer-Incorporated Polymeric Micelles for Enhanced Photodynamic Therapy. Adv. Drug Deliv. Rev. 61 (4), 327-338. doi:10.1016/j.addr.2009.01.004

NobelPrize.org The Nobel Prize in Physiology or Medicine 1903. [Online]. Nobel Media AB 2021. Available: https://www.nobelprize.org/prizes/medicine/1903/ summary/. (Accessed Mon. June 28, 2021).

Nokes, B., Apel, M., Jones, C., Brown, G., and Lang, J. E. (2013). Aminolevulinic Acid (ALA): Photodynamic Detection and Potential Therapeutic Applications. J. Surg. Res. 181 (2), 262-271. doi:10.1016/j.jss.2013.02.002

Nompumelelo Simelane, N. W., Kruger, C. A., and Abrahamse, H. (2020). Photodynamic Diagnosis and Photodynamic Therapy of Colorectal Cancer In Vitro and In Vivo. RSC Adv. 10 (68), 41560-41576. doi:10.1039/d0ra08617g

Nowis, D., Makowski, M., Stokłosa, T., Legat, M., Issat, T., and Gołab, J. (2005). Direct Tumor Damage Mechanisms of Photodynamic Therapy. Acta Biochim. Pol. 52 (2), 339-352. doi:10.18388/abp.2005_3447

NXDC (2018). Gleolan (Aminolevulinic Acid Hydrochloride) [package Insert]. U.S. Food and Drug Administration Website. Revised August 2018. Available at: https://www.accessdata.fda.gov/drugsatfda_docs/label/2018/208630s003lbl. pdf. (Accessed Mar 14, 2021).

O'Connor, A. E., Gallagher, W. M., and Byrne, A. T. (2009). Porphyrin and Nonporphyrin Photosensitizers in Oncology: Preclinical and Clinical Advances in Photodynamic Therapy. Photochem. Photobiol. 85 (5), 1053-1074. doi:10.1111/j.1751-1097.2009.00585.x

Owari, T., Iwamoto, T., Anai, S., Miyake, M., Nakai, Y., Hori, S., et al. (2021). The Sustaining of Fluorescence in Photodynamic Diagnosis after the Administration of 5-aminolevulinic Acid in Carcinogen-Induced Bladder Cancer Orthotopic Rat Model and Urothelial Cancer Cell Lines. Photodiagn. Photodyn. Ther. 34, 102309. doi:10.1016/j.pdpdt.2021.102309

Oyim, J., Omolo, C. A., and Amuhaya, E. K. (2021). Photodynamic Antimicrobial Chemotherapy: Advancements in Porphyrin-Based Photosensitize Development. Front. Chem. 9, 635344. doi:10.3389/fchem.2021.635344
Park, J.-J., Thi, E. P., Carpio, V. H., Bi, Y., Cole, A. G., Dorsey, B. D., et al. (2021). Checkpoint Inhibition through Small Molecule-Induced Internalization of Programmed Death-Ligand 1. Nat. Commun. 12 (1), 1222. doi:10.1038/ s41467-021-21410-1

Pass, H. I. (1993). Photodynamic Therapy in Oncology: Mechanisms and Clinical Use. JNCI J. Natl. Cancer Inst. 85 (6), 443-456. doi:10.1093/jnci/ 85.6.443

Pedone, D., Moglianetti, M., De Luca, E., Bardi, G., and Pompa, P. P. (2017). Platinum Nanoparticles in Nanobiomedicine. Chem. Soc. Rev. 46 (16), 4951-4975. doi:10.1039/c7cs00152e

Pernot, M., Frochot, C., Vanderesse, R., and Barberi-Heyob, M. (2013). "Targeting Strategies in Photodynamic Therapy for Cancer Treatment," in Handbook of Photomedicine. Editors M. R. Hamblin and Y. Huang 1st Edition ed (Boca Raton: CRC Press). doi:10.1201/b15582-35

Persidis, A. (1999). Cancer Multidrug Resistance. Nat. Biotechnol. 17 (1), 94-95. doi:10.1038/5289

Peterson, C. M., Reed, R., Jolles, C. J., Jones, K. P., Straight, R. C., and Poulson, A. M. (1992). Photodynamic Therapy of Human Ovarian Epithelial Carcinoma, OVCAR-3, Heterotransplanted in the Nude Mouse. Am. J. Obstet. Gynecol. 167 (6), 1852-1855. doi:10.1016/0002-9378(92)91786-a

Peterson, C. M., Lu, J. M., Sun, Y., Peterson, C. A., Shiah, J. G., Straight, R. C., et al. (1996). Combination Chemotherapy and Photodynamic Therapy with N-(2hydroxypropyl) Methacrylamide Copolymer-Bound Anticancer Drugs Inhibit Human Ovarian Carcinoma Heterotransplanted in Nude Mice. Cancer Res. 56 (17), 3980-3985.

Photocure ASA (2018). Cysview (Hexaminolevulinate Hydrochloride) [package Insert]. U.S. Food and Drug Administration Website. Revised Februrary 2018. Available at: https://www.accessdata.fda.gov/drugsatfda_docs/label/2018/ 022555s005lbl.pdf. (Accessed Mar 14, 2021).

Pinnacle Biolgs (2020). Photofrin (Porfimer Sodium) [package Insert]. U.S. Food and Drug Administration Website. Revised January 2020. Available at: https:// www.accessdata.fda.gov/drugsatfda_docs/label/2020/020451s029,021525s005lbl. pdf. (Accessed Mar 14, 2021).

Qiu, H., Kim, M. M., Penjweini, R., Finlay, J. C., Busch, T. M., Wang, T., et al. (2017). A Comparison of Dose Metrics to Predict Local Tumor Control for Photofrin-Mediated Photodynamic Therapy. Photochem. Photobiol. 93 (4), 1115-1122. doi:10.1111/php. 12719

Quintana, E., Shackleton, M., Sabel, M. S., Fullen, D. R., Johnson, T. M., and Morrison, S. J. (2008). Efficient Tumour Formation by Single Human Melanoma Cells. Nature 456 (7222), 593-598. doi:10.1038/nature07567

Quirk, B. J., Brandal, G., Donlon, S., Vera, J. C., Mang, T. S., Foy, A. B., et al. (2015). Photodynamic Therapy (PDT) for Malignant Brain Tumors - Where Do We Stand? Photodiagn. Photodyn. Ther. 12 (3), 530-544. doi:10.1016/ j.pdpdt.2015.04.009

Raab, O. (1900). Uber die wirkung Fluorescirender Stoffe auf Infusorien. Z. Biol. $39,524-546$

Railkar, R., and Agarwal, P. K. (2018). Photodynamic Therapy in the Treatment of Bladder Cancer: Past Challenges and Current Innovations. Eur. Urol. Focus 4 (4), 509-511. doi:10.1016/j.euf.2018.08.005

Rapacka-Zdończyk, A., Woźniak, A., Michalska, K., Pierański, M., Ogonowska, P., Grinholc, M., et al. (2021). Factors Determining the Susceptibility of Bacteria to Antibacterial Photodynamic Inactivation. Front. Med. 8, 642609. doi:10.3389/ fmed.2021.642609

Rasmussen-Taxdal, D. S., Ward, G. E., and Figge, F. H. (1955). Fluorescence of Human Lymphatic and Cancer Tissues Following High Doses of Intravenous Hematoporphyrin. Surg. Forum 5, 619-624.

Reginato, E., Wolf, P., and Hamblin, M. R. (2014). Immune Response after Photodynamic Therapy Increases Anti-cancer and Anti-bacterial Effects. Wji 4 (1), 1-11. doi:10.5411/wji.v4.i1.1

Rigual, N. R., Shafirstein, G., Frustino, J., Seshadri, M., Cooper, M., Wilding, G., et al. (2013). Adjuvant Intraoperative Photodynamic Therapy in Head and Neck Cancer. JAMA Otolaryngol. Head Neck Surg. 139 (7), 706-711. doi:10.1001/jamaoto.2013.3387

Ris, H.-B. (2005). Photodynamic Therapy as an Adjunct to Surgery for Malignant Pleural Mesothelioma. Lung Cancer 49 (Suppl. 1), S65-S68. doi:10.1016/ j.lungcan.2005.03.024

Robert, C. (2020). A Decade of Immune-Checkpoint Inhibitors in Cancer Therapy. Nat. Commun. 11 (1), 3801. doi:10.1038/s41467-020-17670-y 
Roelandts, R. (1991). The History of Photochemotherapy. Photodermatol. Photoimmunol Photomed. 8 (5), 184-189.

Rossi, M., Carioli, G., Bonifazi, M., Zambelli, A., Franchi, M., Moja, L., et al. (2016). Trastuzumab for HER2+ Metastatic Breast Cancer in Clinical Practice: Cardiotoxicity and Overall Survival. Eur. J. Cancer 52, 41-49. doi:10.1016/ j.ejca.2015.09.012

Rout, B., Liu, C.-H., and Wu, W.-C. (2017). Photosensitizer in Lipid Nanoparticle: A Nano-Scaled Approach to Antibacterial Function. Sci. Rep. 7 (1), 7892. doi:10.1038/s41598-017-07444-w

Saji, H., Song, W., Furumoto, K., Kato, H., and Engleman, E. G. (2006). Systemic Antitumor Effect of Intratumoral Injection of Dendritic Cells in Combination with Local Photodynamic Therapy. Clin. Cancer Res. 12 (8), 2568-2574. doi:10.1158/1078-0432.CCR-05-1986

Santos, L. L., Oliveira, J., Monteiro, E., Santos, J., and Sarmento, C. (2018). Treatment of Head and Neck Cancer with Photodynamic Therapy with Redaporfin: A Clinical Case Report. Case Rep. Oncol. 11 (3), 769-776. doi:10.1159/000493423

Savellano, M. D., Pogue, B. W., Hoopes, P. J., Vitetta, E. S., and Paulsen, K. D. (2005). Multiepitope HER2 Targeting Enhances Photoimmunotherapy of HER2-Overexpressing Cancer Cells with Pyropheophorbide-A Immunoconjugates. Cancer Res. 65 (14), 6371-6379. doi:10.1158/00085472.CAN-05-0426

Schmidt-Erfurth, U., Miller, J., Sickenberg, M., Bunse, A., Laqua, H., Gragoudas, E., et al. (1998). Photodynamic Therapy of Subfoveal Choroidal Neovascularization: Clinical and Angiographic Examples. Graefe's Archive Clin. Exp. Ophthalmol. 236 (5), 365-374. doi:10.1007/s004170050092

Schmitt, F., and Juillerat-Jeanneret, L. (2012). Drug Targeting Strategies for Photodynamic Therapy. Acamc 12 (5), 500-525. doi:10.2174/ 187152012800617830

Senge, M. O. (2012). mTHPC - A Drug on its Way from Second to Third Generation Photosensitizer? Photodiagn. Photodyn. Ther. 9 (2), 170-179. doi:10.1016/j.pdpdt.2011.10.001

Shen, Z., Ma, Q., Zhou, X., Zhang, G., Hao, G., Sun, Y., et al. (2021). Strategies to Improve Photodynamic Therapy Efficacy by Relieving the Tumor Hypoxia Environment. NPG Asia Mater. 13 (1), 39. doi:10.1038/s41427-021-00303-1

Shi, J., Su, Y., Liu, W., Chang, J., and Zhang, Z. (2017). A Nanoliposome-Based Photoactivable Drug Delivery System for Enhanced Cancer Therapy and Overcoming Treatment Resistance. Ijn Vol. 12, 8257-8275. doi:10.2147/ IJN.S143776

Shirasu, N., Nam, S. O., and Kuroki, M. (2013). Tumor-targeted Photodynamic Therapy. Anticancer Res. 33 (7), 2823-2831.

Shu, M., Yan, H., Xu, C., Wu, Y., Chi, Z., Nian, W., et al. (2020). A Novel AntiHER2 Antibody GB235 Reverses Trastuzumab Resistance in HER2-Expressing Tumor Cells In Vitro and In Vivo. Sci. Rep. 10 (1), 2986. doi:10.1038/s41598020-59818-2

Siegel, R. L., Miller, K. D., and Jemal, A. (2020). Cancer Statistics, 2020. CA A. Cancer J. Clin. 70 (1), 7-30. doi:10.3322/caac. 21590

Sirotkina, M. A., Moiseev, A. A., Matveev, L. A., Zaitsev, V. Y., Elagin, V. V., Kuznetsov, S. S., et al. (2019). Accurate Early Prediction of Tumour Response to PDT Using Optical Coherence Angiography. Sci. Rep. 9 (1), 6492. doi:10.1038/ s41598-019-43084-y

Song, W., Kuang, J., Li, C.-X., Zhang, M., Zheng, D., Zeng, X., et al. (2018). Enhanced Immunotherapy Based on Photodynamic Therapy for Both Primary and Lung Metastasis Tumor Eradication. ACS Nano. 12 (2), 1978-1989. doi:10.1021/acsnano.7b09112

Sorrin, A. J., Kemal Ruhi, M., Ferlic, N. A., Karimnia, V., Polacheck, W. J., Celli, J. P., et al. (2020). Photodynamic Therapy and the Biophysics of the Tumor Microenvironment. Photochem. Photobiol. 96 (2), 232-259. doi:10.1111/ php.13209

Spikes, J. D. (1990). New Trends in Photobiology. J. Photochem. Photobiol. B: Biol. 6 (3), 259-274. doi:10.1016/1011-1344(90)85096-f

Staneloudi, C., Smith, K. A., Hudson, R., Malatesti, N., Savoie, H., Boyle, R. W., et al. (2007). Development and Characterization of Novel Photosensitizer : $\mathrm{scFv}$ Conjugates for Use in Photodynamic Therapy of Cancer. Immunology 120 (4), 512-517. doi:10.1111/j.1365-2567.2006.02522.x

Stenson, K. M. (2021). in Epidemiology and Risk Factors for Head and Neck Cancer. Editor T.W. Post (Waltham, MA: UpToDate)).
Stolik, S., Delgado, J. A., Pérez, A., and Anasagasti, L. (2000). Measurement of the Penetration Depths of Red and Near Infrared Light in Human "Ex Vivo" Tissues. J. Photochem. Photobiol. B 57 (2-3), 90-93. doi:10.1016/s1011-1344(00) 00082-8

Stummer, W., Pichlmeier, U., Meinel, T., Wiestler, O. D., Zanella, F., Reulen, H.-J., et al. (2006). Fluorescence-guided Surgery with 5-aminolevulinic Acid for Resection of Malignant Glioma: a Randomised Controlled Multicentre Phase III Trial. Lancet Oncol. 7 (5), 392-401. doi:10.1016/S1470-2045(06) 70665-9

Sun, B., Li, W., and Liu, N. (2016). Curative Effect of the Recent Photofrin Photodynamic Adjuvant Treatment on Young Patients with Advanced Colorectal Cancer. Oncol. Lett. 11 (3), 2071-2074. doi:10.3892/ol.2016.4179

Sung, H., Ferlay, J., Siegel, R. L., Laversanne, M., Soerjomataram, I., Jemal, A., et al. (2021). Global Cancer Statistics 2020: GLOBOCAN Estimates of Incidence and Mortality Worldwide for 36 Cancers in 185 Countries. CA A. Cancer J. Clin. 71 (3), 209-249. doi:10.3322/caac. 21660

Tappeiner, H. (1909). Die photodynamische Erscheinung (Sensibilisierung durch fluoreszierende Stoffe). Ergebnisse der Physiologie 8 (1), 698-741. doi:10.1007/ bf0232109610.1007/bf01951514

Torres, T., Fernandes, I., Costa, V., and Selores, M. (2011). Photodynamic Therapy as Adjunctive Therapy for Morpheaform Basal Cell Carcinoma. Acta Dermatovenerol Alp Pannonica Adriat 20 (1), 23-25.

Trempolec, N., Doix, B., Degavre, C., Brusa, D., Bouzin, C., Riant, O., et al. (2020). Photodynamic Therapy-Based Dendritic Cell Vaccination Suited to Treat Peritoneal Mesothelioma. Cancers 12 (3), 545. doi:10.3390/cancers12030545

Triesscheijn, M., Baas, P., Schellens, J. H. M., and Stewart, F. A. (2006). Photodynamic Therapy in Oncology. Oncologist 11 (9), 1034-1044. doi:10.1634/theoncologist.11-9-1034

Turan, I. S., Yildiz, D., Turksoy, A., Gunaydin, G., and Akkaya, E. U. (2016). A Bifunctional Photosensitizer for Enhanced Fractional Photodynamic Therapy: Singlet Oxygen Generation in the Presence and Absence of Light. Angew. Chem. Int. Ed. 55 (8), 2875-2878. doi:10.1002/anie.201511345

Turan, I. S., Gunaydin, G., Ayan, S., and Akkaya, E. U. (2018). Molecular Demultiplexer as a Terminator Automaton. Nat. Commun. 9 (1), 805. doi:10.1038/s41467-018-03259-z

Urbach, F., Forbes, P. D., Davies, R. E., and Berger, D. (1976). Cutaneous Photobiology: Past, Present and Future. J. Invest. Dermatol. 67 (1), 209-224. doi:10.1111/1523-1747.ep12513042

Usuda, J., Kato, H., Okunaka, T., Furukawa, K., Tsutsui, H., Yamada, K., et al. (2006). Photodynamic Therapy (PDT) for Lung Cancers. J. Thorac. Oncol. 1 (5), 489-493. doi:10.1016/S1556-0864(15)31616-6

van Doeveren, T. E. M., Karakullukçu, M. B., van Veen, R. L. P., Lopez-Yurda, M., Schreuder, W. H., and Tan, I. B. (2018). Adjuvant Photodynamic Therapy in Head and Neck Cancer after Tumor-Positive Resection Margins. Laryngoscope 128 (3), 657-663. doi:10.1002/lary.26792

van Straten, D., Mashayekhi, V., de Bruijn, H., Oliveira, S., and Robinson, D. (2017). Oncologic Photodynamic Therapy: Basic Principles, Current Clinical Status and Future Directions. Cancers 9 (2), 19. doi:10.3390/cancers9020019

Vander Heiden, M. G., Cantley, L. C., and Thompson, C. B. (2009). Understanding the Warburg Effect: The Metabolic Requirements of Cell Proliferation. Science 324 (5930), 1029-1033. doi:10.1126/science.1160809

Verger, A., Brandhonneur, N., Molard, Y., Cordier, S., Kowouvi, K., Amela-Cortes, M., et al. (2021). From Molecules to Nanovectors: Current State of the Art and Applications of Photosensitizers in Photodynamic Therapy. Int. J. Pharmaceutics 604, 120763. doi:10.1016/j.ijpharm.2021.120763

Wang, Z., Ma, R., Yan, L., Chen, X., and Zhu, G. (2015). Combined Chemotherapy and Photodynamic Therapy Using a Nanohybrid Based on Layered Double Hydroxides to Conquer Cisplatin Resistance. Chem. Commun. 51 (58), 11587-11590. doi:10.1039/c5cc04376j

Wang, D., Wang, T., Liu, J., Yu, H., Jiao, S., Feng, B., et al. (2016). Acid-Activatable Versatile Micelleplexes for PD-L1 Blockade-Enhanced Cancer Photodynamic Immunotherapy. Nano Lett. 16 (9), 5503-5513. doi:10.1021/ acs.nanolett.6b01994

Wang, X., Ramamurthy, G., Shirke, A. A., Walker, E., Mangadlao, J., Wang, Z., et al. (2020a). Photodynamic Therapy Is an Effective Adjuvant Therapy for ImageGuided Surgery in Prostate Cancer. Cancer Res. 80 (2), 156-162. doi:10.1158/ 0008-5472.CAN-19-0201 
Wang, Y., Wang, H., Zhou, L., Lu, J., Jiang, B., Liu, C., et al. (2020b). Photodynamic Therapy of Pancreatic Cancer: Where Have We Come from and where Are We Going? Photodiagn. Photodyn. Ther. 31, 101876. doi:10.1016/ j.pdpdt.2020.101876

Wang, K., Yu, B., and Pathak, J. L. (2021). An Update in Clinical Utilization of Photodynamic Therapy for Lung Cancer. J. Cancer 12 (4), 1154-1160. doi:10.7150/jca. 51537

Warrier, A., Mazumder, N., Prabhu, S., Satyamoorthy, K., and Murali, T. S. (2021). Photodynamic Therapy to Control Microbial Biofilms. Photodiagnosis Photodynamic Ther. 33, 102090. doi:10.1016/j.pdpdt.2020.102090

Wieder, M. E., Hone, D. C., Cook, M. J., Handsley, M. M., Gavrilovic, J., and Russell, D. A. (2006). Intracellular Photodynamic Therapy with Photosensitizer-Nanoparticle Conjugates: Cancer Therapy Using a 'Trojan Horse'. Photochem. Photobiol. Sci. 5 (8), 727-734. doi:10.1039/b602830f

Wilson, B. C., and Patterson, M. S. (2008). The Physics, Biophysics and Technology of Photodynamic Therapy. Phys. Med. Biol. 53 (9), R61-R109. doi:10.1088/ 0031-9155/53/9/R01

Wöhrle, D., Hirth, A., Bogdahn-Rai, T., Schnurpfeil, G., and Shopova, M. (1998). Photodynamic Therapy of Cancer: Second and Third Generations of Photosensitizers. Russ. Chem. Bull. 47 (5), 807-816. doi:10.1007/bf02498146

Xu, J., Xu, L., Wang, C., Yang, R., Zhuang, Q., Han, X., et al. (2017). Near-InfraredTriggered Photodynamic Therapy with Multitasking Upconversion Nanoparticles in Combination with Checkpoint Blockade for Immunotherapy of Colorectal Cancer. ACS Nano 11 (5), 4463-4474. doi:10.1021/acsnano.7b00715

Xu, J., Saklatvala, R., Mittal, S., Deshmukh, S., and Procopio, A. (2020). Recent Progress of Potentiating Immune Checkpoint Blockade with External StimuliAn Industry Perspective. Adv. Sci. 7 (8), 1903394. doi:10.1002/advs.201903394

Yang, L., Zhang, S., Ling, X., Shao, P., Jia, N., and Bai, M. (2017). Multilayer Photodynamic Therapy for Highly Effective and Safe Cancer Treatment. Acta Biomater. 54, 271-280. doi:10.1016/j.actbio.2017.03.012

Yang, H., Liu, R., Xu, Y., Qian, L., and Dai, Z. (2021). Photosensitizer Nanoparticles Boost Photodynamic Therapy for Pancreatic Cancer Treatment. Nano-micro Lett. 13 (1), 35. doi:10.1007/s40820-020-00561-8

Yanovsky, R. L., Bartenstein, D. W., Rogers, G. S., Isakoff, S. J., and Chen, S. T. (2019). Photodynamic Therapy for Solid Tumors: A Review of the Literature. Photodermatol. Photoimmunol Photomed. 35 (5), 295-303. doi:10.1111/ phpp.12489

Yin, T., Wang, Z., Li, X., Li, Y., Bian, K., Cao, W., et al. (2017). Biologically Inspired Self-Assembly of Bacitracin-Based Platinum Nanoparticles with Anti-tumor Effects. New J. Chem. 41 (8), 2941-2948. doi:10.1039/c6nj03302d

Yoo, J.-O., and Ha, K.-S. (2012). New Insights into the Mechanisms for Photodynamic Therapy-Induced Cancer Cell Death. Int. Rev. Cel Mol Biol. 295, 139-174. doi:10.1016/B978-0-12-394306-4.00010-1

Yu, X., Ghamande, S., Liu, H., Xue, L., Zhao, S., Tan, W., et al. (2018). Targeting EGFR/HER2/HER3 with a Three-In-One Aptamer-siRNA Chimera Confers Superior Activity against HER2+ Breast Cancer. Mol. Ther. - Nucleic Acids 10, 317-330. doi:10.1016/j.omtn.2017.12.015

Zeitouni, N. C., Shieh, S., and Oseroff, A. R. (2001). Laser and Photodynamic Therapy in the Management of Cutaneous Malignancies. Clin. Dermatol. 19 (3), 328-338. doi:10.1016/s0738-081x(01)00170-5
Zhang, Q., Cai, Y., Li, Q.-Y., Hao, L.-N., Ma, Z., Wang, X.-J., et al. (2017). Targeted Delivery of a Mannose-Conjugated BODIPY Photosensitizer by Nanomicelles for Photodynamic Breast Cancer Therapy. Chem. Eur. J. 23 (57), 14307-14315. doi:10.1002/chem.201702935

Zhang, H., Wang, P., Wang, X., Shi, L., Fan, Z., Zhang, G., et al. (2018a). Antitumor Effects of DC Vaccine With ALA-PDT-Induced Immunogenic Apoptotic Cells for Skin Squamous Cell Carcinoma in Mice. Technol. Cancer Res. Treat. 17, 153303381878527. doi:10.1177/1533033818785275

Zhang, J., Zhang, S., Liu, Y., Su, M., Ling, X., Liu, F., et al. (2018b). Combined CB2 Receptor Agonist and Photodynamic Therapy Synergistically Inhibit Tumor Growth in Triple Negative Breast Cancer. Photodiagn. Photodyn. Ther. 24, 185-191. doi:10.1016/j.pdpdt.2018.09.006

Zhang, Q., Wu, L., Liu, S., Chen, Q., Zeng, L., Chen, X., et al. (2020). Targeted Nanobody Complex Enhanced Photodynamic Therapy for Lung Cancer by Overcoming Tumor Microenvironment. Cancer Cel Int 20 (1), 570. doi:10.1186/s12935-020-01613-0

Zhang, Z., Li, A., Min, X., Zhang, Q., Yang, J., Chen, G., et al. (2021). An ROSSensitive Tegafur-PpIX-Heterodimer-Loaded In Situ Injectable Thermosensitive Hydrogel for Photodynamic Therapy Combined with Chemotherapy to Enhance the Tegafur-Based Treatment of Breast Cancer. Biomater. Sci. 9 (1), 221-237. doi:10.1039/d0bm01519a

Zhao, C.-Y., Cheng, R., Yang, Z., and Tian, Z.-M. (2018). Nanotechnology for Cancer Therapy Based on Chemotherapy. Molecules 23 (4), 826. doi:10.3390/ molecules23040826

Zhao, X., Liu, J., Fan, J., Chao, H., and Peng, X. (2021). Recent Progress in Photosensitizers for Overcoming the Challenges of Photodynamic Therapy: from Molecular Design to Application. Chem. Soc. Rev. 50 (6), 4185-4219. doi:10.1039/d0cs00173b

Zhou, Q., Olivo, M., Lye, K. Y. K., Moore, S., Sharma, A., and Chowbay, B. (2005). Enhancing the Therapeutic Responsiveness of Photodynamic Therapy with the Antiangiogenic Agents SU5416 and SU6668 in Murine Nasopharyngeal Carcinoma Models. Cancer Chemother. Pharmacol. 56 (6), 569-577. doi:10.1007/s00280-005-1017-0

Conflict of Interest: The authors declare that the research was conducted in the absence of any commercial or financial relationships that could be construed as a potential conflict of interest.

Publisher's Note: All claims expressed in this article are solely those of the authors and do not necessarily represent those of their affiliated organizations, or those of the publisher, the editors and the reviewers. Any product that may be evaluated in this article, or claim that may be made by its manufacturer, is not guaranteed or endorsed by the publisher.

Copyright (c) 2021 Gunaydin, Gedik and Ayan. This is an open-access article distributed under the terms of the Creative Commons Attribution License (CC $B Y)$. The use, distribution or reproduction in other forums is permitted, provided the original author(s) and the copyright owner(s) are credited and that the original publication in this journal is cited, in accordance with accepted academic practice. No use, distribution or reproduction is permitted which does not comply with these terms. 


\section{GLOSSARY}

ADP adenosine diphosphate

AK actinic keratosis

ALA aminolevulinic acid

ATP adenosine triphosphate

CTLA-4 cytotoxic T lymphocyte-associated protein 4

ECM extracellular matrix

EET excitation energy transfer

EMA european medicines agency

FDA food and drug administration

GLUT glucose transporter

HER2 human epidermal growth factor receptor 2

HpD hematoporphyrin derivative

HPPH 2-(1-hexyloxyethyl)-2-devinyl pyropheophorbide-a

IC internal conversion

IDO indoleamine-2,3-dioxygenase

IFN $\boldsymbol{\gamma}$ interferon gamma

ISC intersystem crossing
LED light emitting diodes

MAL methyl aminolevulinate

MDR multidrug resistance

MLu motexafin lutetium

MRI magnetic resonance imaging

mTHPC $m$-tetrahydroxyphenylchlorin

NIR near-infrared

NSCLC non-small-cell lung cancer

PD-1 programmed cell death protein 1

PDD photodynamic diagnosis

PDK pyruvate dehydrogenase kinase

PD-L1 programmed cell death 1 ligand 1

PDT photodynamic therapy

PIT photoimmunotherapy

PpIX protoporphyrin IX

PS photosensitizer

ROS reactive oxygen species

UV ultraviolet

VEGF vascular endothelial growth factor 